\title{
"Internet+" approach to mapping exposure and seismic vulnerability of buildings in a context of rapid socioeconomic growth: a case study in Tangshan, China
}

\author{
Wenhua $\mathrm{Qi}^{1} \cdot$ Guiwu $\mathrm{Su}^{1} \cdot$ Lei $\mathrm{Sun}^{1} \cdot$ Fan Yang $^{2}$. \\ Yang $\mathrm{Wu}^{1}$
}

Received: 7 January 2016/Accepted: 2 September 2016/Published online: 15 September 2016

(C) The Author(s) 2016. This article is published with open access at Springerlink.com

\begin{abstract}
This paper presents the development of an "Internet+" approach to mapping exposure and seismic vulnerability of buildings in a context of rapid socioeconomic growth. This approach is a combination of the following interdependent components: (1) extraction of footprint areas of a large number of buildings from high-resolution Google Earth images; (2) estimation of floor numbers of these buildings with an integrated use of high-resolution Google Earth images, Tencent/Baidu Street Views, crowdsourcing data, and associated building-relevant local knowledge; and (3) identification of structural types of these buildings by a combined use of crowdsourcing data and associated buildingrelevant local knowledge. The efficacy of this "Internet+" approach was demonstrated through an application in Tangshan, China. Field-based verification indicated that the overall mean absolute percentage error of the proposed "Internet+" approach in assessing the total floor area of the addressed buildings was $4.64 \%$. The verification also showed that the overall consistency between the estimated structural types using the proposed approach and the actual structural types of the buildings with structural type uncertainties could reach $97.54 \%$, with a kappa coefficient of 0.94 . Because of its good accuracy, noteworthy speed, substantial labor savings, negligible cost and distinctive capability in covering large areas in near real time, this "Internet+" approach might have promising prospects in actual seismic loss risk reduction challenges.
\end{abstract}

Keywords Internet+ $\cdot$ Google Earth image $\cdot$ Tencent/Baidu Street Views ·

Crowdsourcing $\cdot$ Exposure and seismic vulnerability of buildings $\cdot$ Rapid socioeconomic growth

Guiwu Su

suguiwu@ies.ac.cn

1 Institute of Geology, China Earthquake Administration, Beijing, China

2 Earthquake Administration of Hebei Province, Shijiazhuang, China 


\section{Introduction}

Seismic exposures, vulnerabilities, and disaster risks are constantly and significantly changing in earthquake-prone areas where rapid socioeconomic development and urbanization is occurring. These changes have made it difficult to ensure that earthquake disaster risk reduction strategies for such an area remain fact-based and effective over time. Certain strategies may become irrelevant after a short period. To prevent this from happening, associated changes in exposures and vulnerabilities must be captured quickly and accurately to perform timely and pertinent adjustments.

There are generally three major types of methods for analyzing seismic exposures, vulnerabilities, and risks: (1) the conventional and mainstream loss ratio curve (LRC) and/ or damaged probability matrix (DPM)-based methods (e.g., ATC 1985; FEMA 1999; Grünthal 1998; Inel et al. 2008; Ploeger et al. 2010), (2) exposure and vulnerability ( $E$ and $V$ ) or vulnerability $(V)$ composite index-focused methods (e.g., Carreño et al. 2007; Cutter et al. 2003; Cutter and Finch 2008; Su et al. 2007), and (3) remote sensing (RS)-based $E$ and/or $V$ methods (e.g., Ehrlich et al. 2010, 2013; Geiß et al. 2014, 2015, 2016; Pittore and Wieland 2013; Taubenböck et al. 2009; Wieland et al. 2012) (for more, please see Table 1). The conventional LRC and/or DPM-based methods can yield definite and accurate exposure, vulnerability, and risk results. However, they usually require significant labor, money, and time. For addressing seismic disaster risks over a large area with rapid socioeconomic development in an accurate and timely manner, applying this type of methods may be difficult or impossible. The $E$ and/or $V$ composite index-focused methods save considerable labor, money, and time and easily cover large areas, but they can only provide general, relative, and highly composite results. According to such kinds of results, it is not always easy to determine what elements on the ground at a given location are at risk and how serious the hidden problems are. Remote sensing technologies have a great advantage in overcoming the timeliness and coverage problems over the former two types of methods when addressing seismic exposure, vulnerability, and loss risks in a context of rapid socioeconomic growth. Because remote sensing images, especially those with high resolutions, may be the only currently practical and reliable tools that are capable of providing full, clear, and timely coverage of large areas when labor resources and work times are limited, while this information is urgently needed. Recently, many studies have addressed the application of remote sensing technologies (esp. with high-resolution) to preearthquake exposure, vulnerability, and risk analysis. These include various single optical imagery-based analyses, some studies on integrating multi-sensors, a few attempts at combining remote sensing data and other critical information, and several comprehensive reviews (Table 1). However, several large gaps exist currently between what remote sensing can provide and mainstream LRC and/or DPM-based exposure, vulnerability, and loss risk estimates specifically require when facing a large number of buildings in an area with rapid socioeconomic changes. Among them, the most important includes: (1) it is still difficult to use remote sensing alone to directly produce some of those core information that are essential for quantitatively and specifically characterizing seismic vulnerabilities and loss risks, such as building structural types and DPMs. (2) High-resolution remote sensing imagery contains important information (e.g., footprint areas of buildings) that can be used to characterize seismic exposures and loss risks in detail. However, the techniques for accurately extracting such information have not been sufficiently developed if a large number of objects (e.g., a large number of buildings) need to be addressed over a limited 


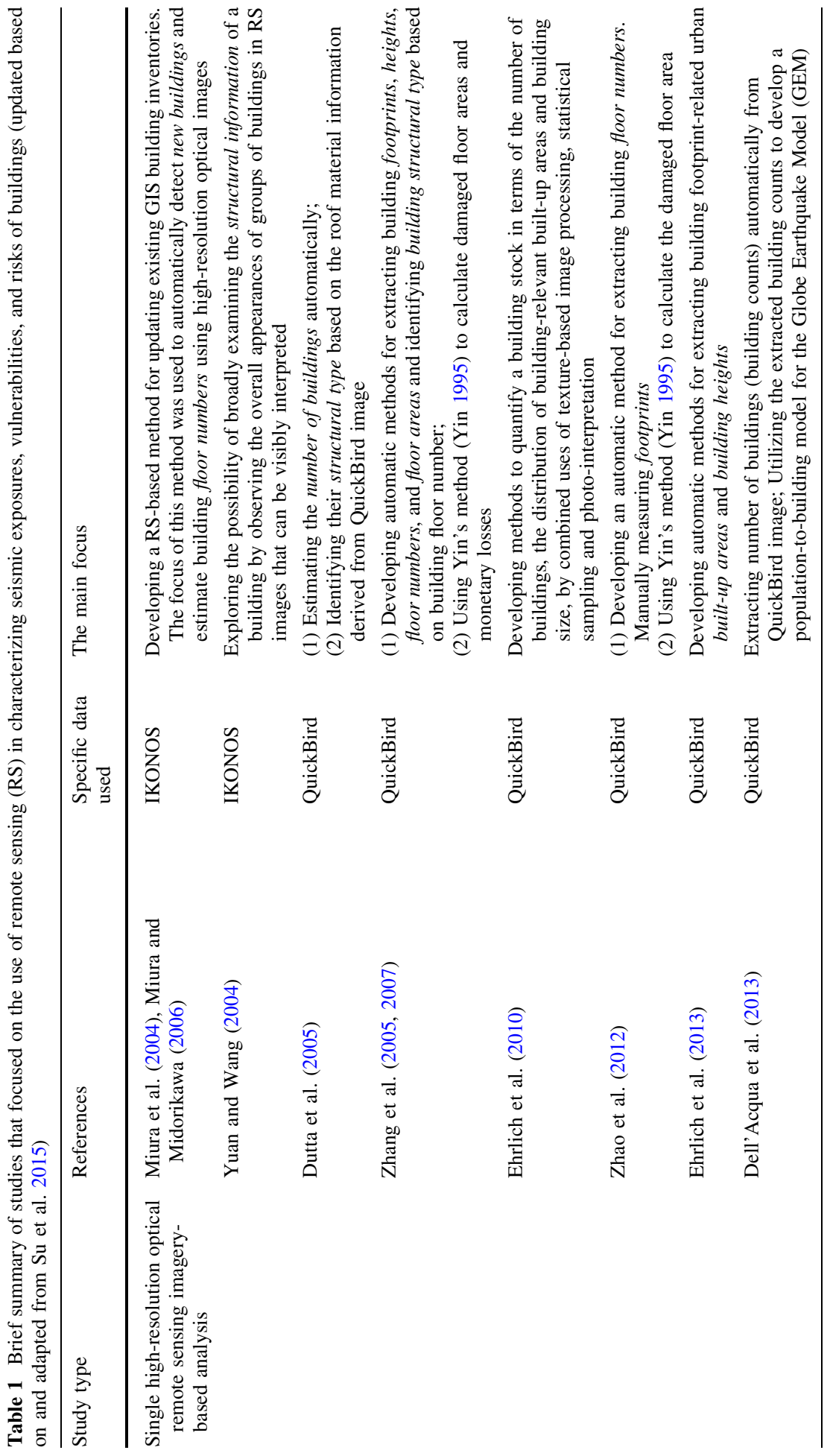




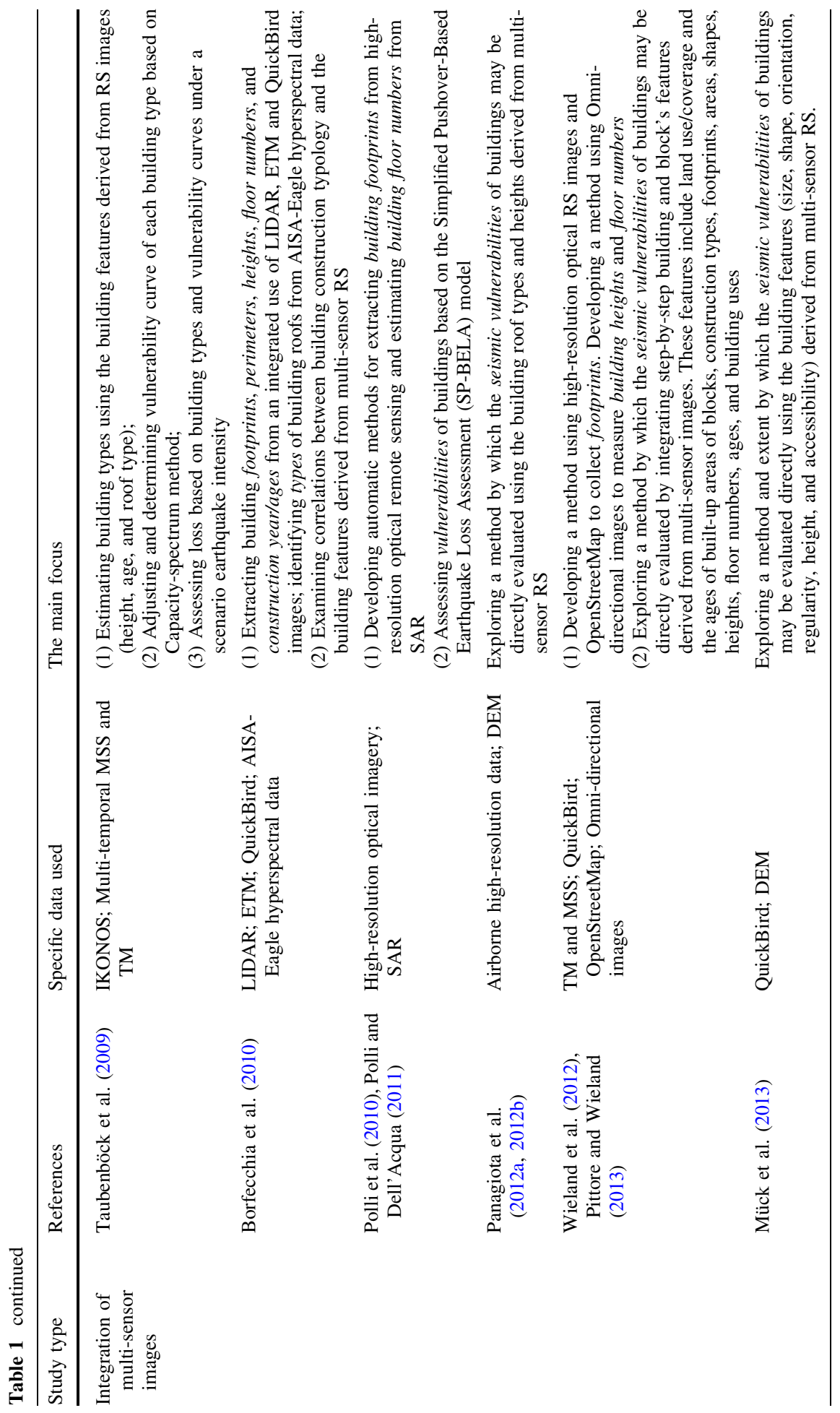




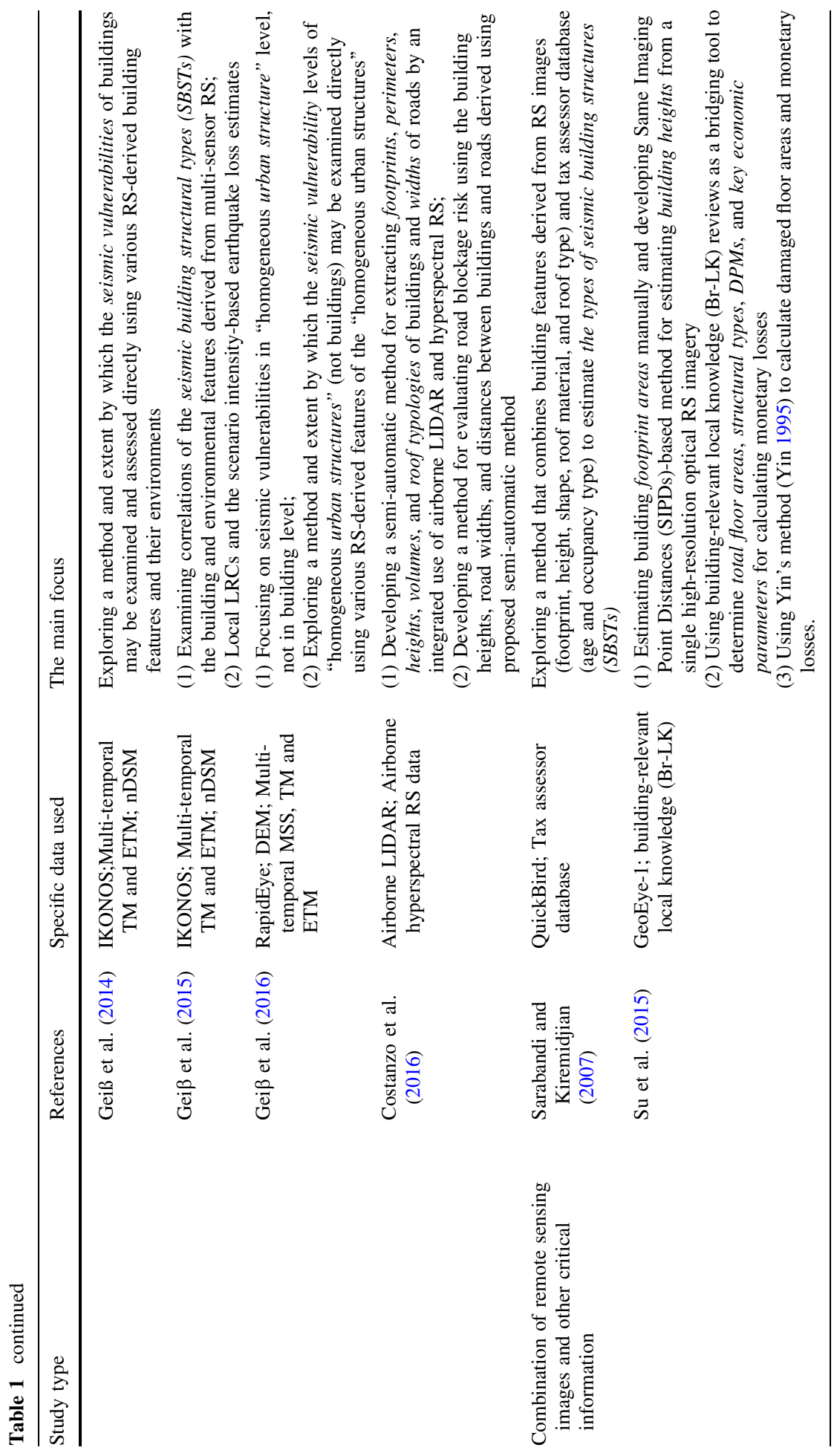




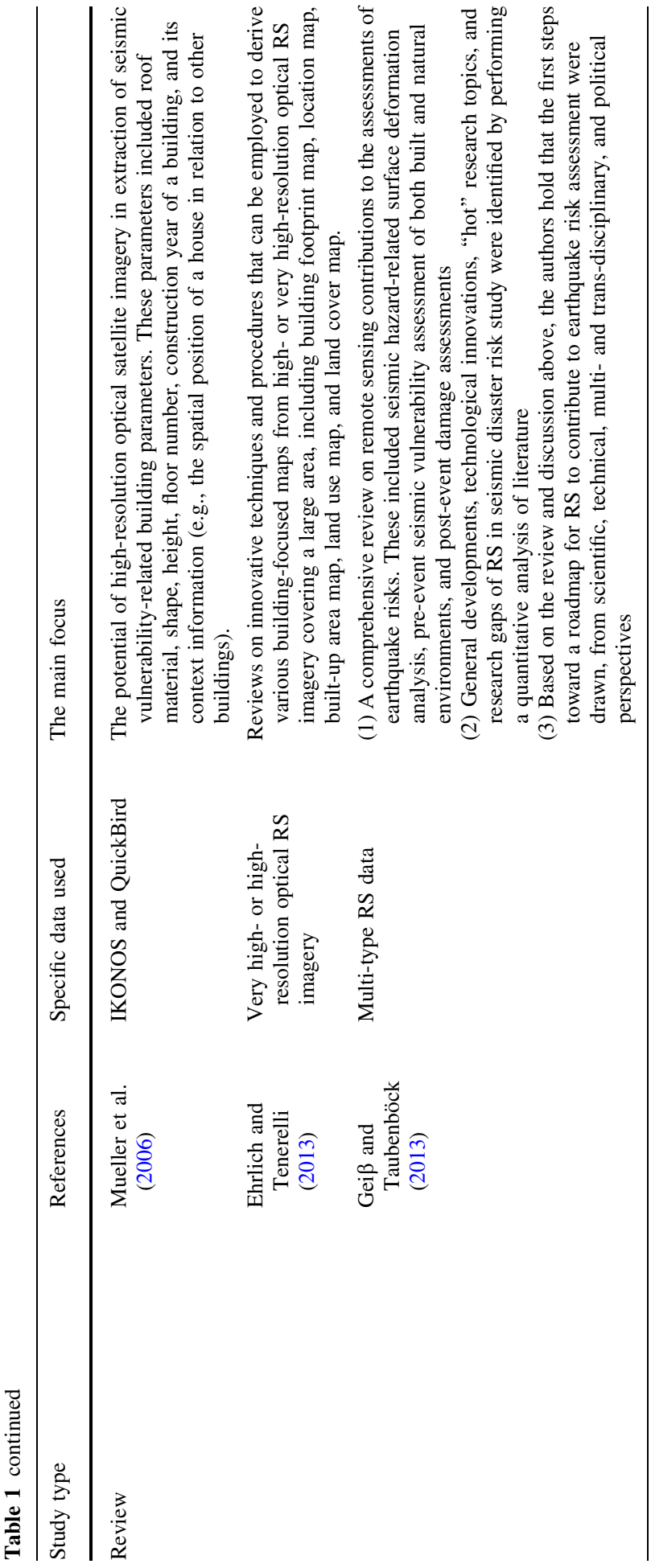


work time. Bridging such gaps is important for promoting deep and practice-aimed applications of remote sensing in broad seismic vulnerability and loss risk reduction fields.

By focusing on residential and public office buildings, we proposed using buildingrelevant local knowledge (Br-LK) reviews to "bridge" these gaps in our previous study (Su et al. 2015). However, several weaknesses exist in our previous method, which challenges its broader application. They are (1) the financial infeasibility of covering very large areas, because high-resolution optical remote sensing images remain expensive, (2) the uncertainty when addressing buildings with floor number-structural type correlations that are not that regular as compared to those observed in Tangshan (the study area of our previous study), (3) the inevitable inaccuracy in identifying structural types of those one to six-floor high buildings among which structural type uncertainties occurred most frequently, and with the rapid socioeconomic development of the area, this inaccuracy occurs more and more often, and (4) the incapability of addressing specially structured buildings. Building on the basic logic of our previous study, this current study intends to develop an "Internet+" approach to continue grappling with the issue: how to capture seismic exposures, vulnerabilities, and their changing scenarios over large areas with rapid socioeconomic growth and city expansions in a timely and accurate manner.

With the rapid development of internet and modern information technologies, online resources have increased dramatically. They are both available to the public and open to the public submissions of geographic data and information through internet-based platforms. Some studies have shown that the data and information provided by the public and non-official institutions are even more detailed (De Longueville et al. 2010; Elwood 2008; Gill and Bunker 2012; Goodchild 2007). The "Internet+" approach proposed in this study is built on a combined utilization of various online heterogeneous building-relevant resources and internet-based platforms. These resources and platforms can be broadly divided into two categories: online mapping and crowdsourcing information. The former includes Google Earth (GE) images and Baidu/Tencent Street Views; the latter includes information provided by various open social and building business Web sites, buildingrelevant Volunteered Geographic Information (VGI), and modern communication modebased instant messages.

Currently, GE images cover most urban areas in Mainland China (Zhou and Luo 2009). Because GE is free and is integrated with GPS and GIS, the service has found numerous applications in a wide variety of scientific disciplines. According to the reviews of Goodchild (2008), Stensgaard et al. (2009), and Yu and Gong (2012), the use of GE in research and application has covered many categories, such as visualization, data collection, exploration and integration, modeling and simulation, communication of research results, and decision-making support. In natural hazard and disaster research, many GEbased studies have also been reported. For example, Nourbakhsh et al. (2006) argued that GE was an effective tool in providing post-disaster images during relief efforts. Webley et al. (2009) used GE to display the volcanic ash dispersion process in the North Pacific region forecasted using the Puff model. Costanzo et al. (2012) produced a landslide archive by exploiting GE for assessing landslide susceptibility in central Sicily, Italy. Ruan and Jia (2013) and Madadi et al. (2015) employed GE to depict and display possible extent of flooding. GE is also a currently attractive topic in earthquake hazard and disaster studies. Existing applications primarily focus on (1) visualizing hazard and disaster events (Agnew 2009; Huang et al. 2011; Li 2009; USGS 2015), (2) assessing ongoing disasters (Gao and Wu 2014; Kayen et al. 2008; Lang and Vladimir 2010; Li et al. 2015; Sato and Harp 2009), (3) supporting emergency decision making (Chen et al. 2008; Nourbakhsh et al. 2006; Yin et al. 2009), and (4) seismic science research (Fisher et al. 2012; Gordon 2014; Li et al. 
2007; Shuai et al. 2011). Street View as another category of online mapping can offer visual scenes of streets and adjacent buildings. Since it appeared, Street View has been increasingly used in people's daily lives. Combined with GIS and associated thematic information, Street View has also begun to play important roles in some professional fields. For example, in the field of hazard mitigation and disaster reduction, Wang (2015) pointed out that Street View could be used to estimate landslide volumes; after Typhoon Fitow hit Zhejiang Province, China, in 2013, Street View was used to map the key relief supplieswanted spots (IFN 2013). This current study intends to use GE images and Tencent/Baidu Street Views to characterize the exposure of residential and public office buildings in the period of pre-earthquake (i.e., non-disaster time of a disaster cycle), on which existing GEor Street View-focused applications are very limited.

The crowdsourcing geographic information refers to spatial information and data that are produced and disseminated onto the web by ordinary citizens or non-official institutions (Gill and Bunker 2012; Goodchild 2007; Heipke 2010). Compared with conventional approaches, the acquisition of crowdsourcing data is in near real time and at low monetary cost (Goodchild and Glennon 2010; Yang et al. 2014). However, crowdsourcing data can be regarded as lacking credibility and reliability sometimes, because it is produced by nonexperts (Elwood 2008; Foody et al. 2013). Even so, crowdsourcing has been widely used in disaster management, especially in during and post-disaster response phases. For example, Goodchild and Glennon (2010) studied crowdsourcing geographic information application in disaster response during the Santa Barbara wildfires of 2007-2009. Gao et al. (2011) noted that crowdsourcing applications based on social media such as Twitter and Ushahidi could offer a powerful capacity for collecting information from disaster scenes and providing visualizing information for relief decision making. The studies of Hyvärinen and Saltikoff (2010), McDougall (2011), Poser and Dransch (2010), and Schnebele and Cervone (2013) described how to use crowdsourcing geographic information to estimate flood inundation depth and map flood extent. In earthquake disaster study field, the USGS Earthquake Hazards Program established a portal for earthquake mapping called "Did You Feel It?" This portal is used to collect experiences from people who were affected by an earthquake (Mark and Schorlemmer 2016; Wald et al. 1999). Zook et al. (2010) outlined how crowdsourcing information related to disaster situation could be collected and combined by using various web-based mapping services, such as CrisisCamp Haiti, OpenStreetMap, Ushahidi, and GeoCommons, and then guiding responses to the Haiti earthquake. Compared with these usages in during and post-disaster response period, the use of crowdsourcing geographic information for pre-disaster risk analysis has not received the same attention (Haworth and Bruce 2015; Horita et al. 2013). Dufty (2012) argued that crowdsourcing information has great potential in improving pre-disaster resilience analysis. Recently, Schelhorn et al. (2014) attempted to identify essential facilities (e.g., hospitals, schools, and police stations) at flood risk from OpenStreetMap to facilitate vulnerability and risk assessment. With these enlightening, this current study intends to use crowdsourcing information to characterize the vulnerabilities of residential and public office buildings in pre-earthquake time, on which existing crowdsourcing-focused studies are also considerably limited.

Given the above, we intend to use such kinds of "Internet+" ideas as main tools and BrLK reviews as auxiliary supplements to address the specific issues of this current study: mapping building exposures and seismic vulnerabilities during pre-earthquake period. By fully combining the advantages of both of these two sides, the accuracy and timeliness were both enhanced when mapping seismic exposures and vulnerabilities across a large area with rapid socioeconomic growth. In the work of conventional LRC- and/or DPM- 

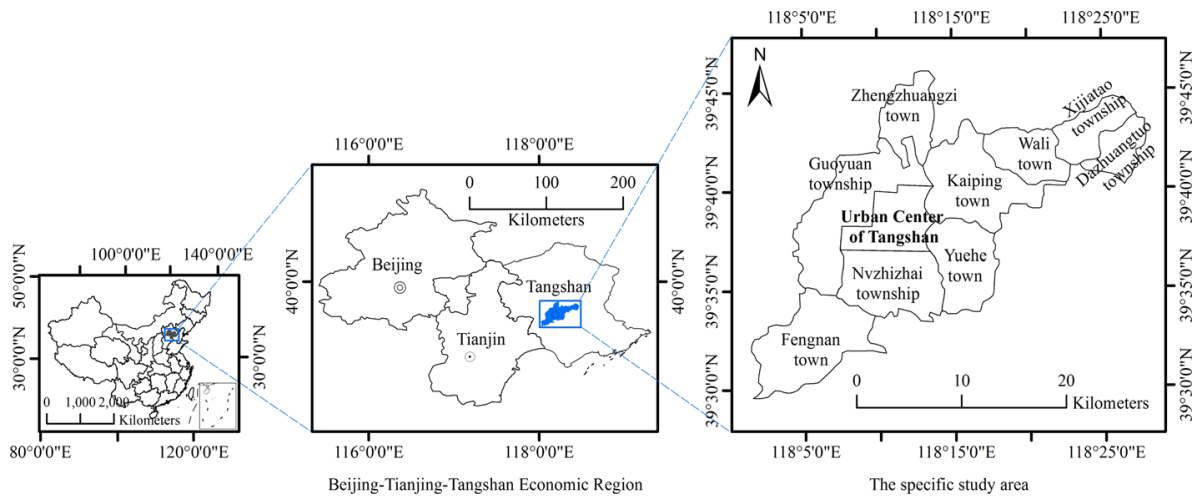

Fig. 1 Location of the study area

based earthquake loss estimation, the exposure of a building refers to its total floor area, and the vulnerability of that building depends on its seismic structural type. In terms of the classification of seismic structural types of buildings, the classification system developed by Yin (1991) was used in this study. Yin's classification system is the most established and commonly used system for classifying the seismic structural types of buildings both in pre-earthquake disaster risk assessment (SAC 2014) and in post-earthquake loss estimation (SAC 2011) in Mainland China. In this system, buildings are assigned to the following five categories: (1) earth/wood buildings (E/W buildings); (2) single-story brick buildings (S/B buildings); (3) brick and concrete buildings (B/C buildings); (4) reinforced concrete buildings (R/C buildings); and (5) specially structured buildings. And all of the residential and public office buildings in Mainland China belong to the first four types in this classification system. For consistency and comparison with our previous study, we continued focusing on residential and public office buildings for analysis and selected still the central part of Tangshan (Fig. 1) as the case study area to demonstrate the development and use of our "Internet+" approach.

\section{Outline of the proposed approach and data}

\subsection{Outline of the proposed approach}

The overall framework of the proposed "Internet+" approach is illustrated in Fig. 2. Specifically, it consists of the following three main interdependent components: (1) extracting footprint areas of a large number of residential and public office buildings from GE images (see Sect. 3); (2) developing correlations between Same Imaging Point Distances (SIPDs) and floor numbers of these buildings by an integrated utilization of GE images, Tencent/Baidu Street Views, crowdsourcing data (WeChat messages and VGI), and associated $\mathrm{Br}-\mathrm{LK}$, and then estimating their floor numbers and further their floor areas using these correlations accordingly (see Sect. 4); and (3) identifying structural types of these buildings by a combined use of crowdsourcing data (online building business data, building information on socioeconomic institution portal Web sites, WeChat messages, and VGI) and associated Br-LK (see Sect. 5). Using this "Internet+" approach, the total floor area of every residential and public office building in 2015 in the study area was estimated 


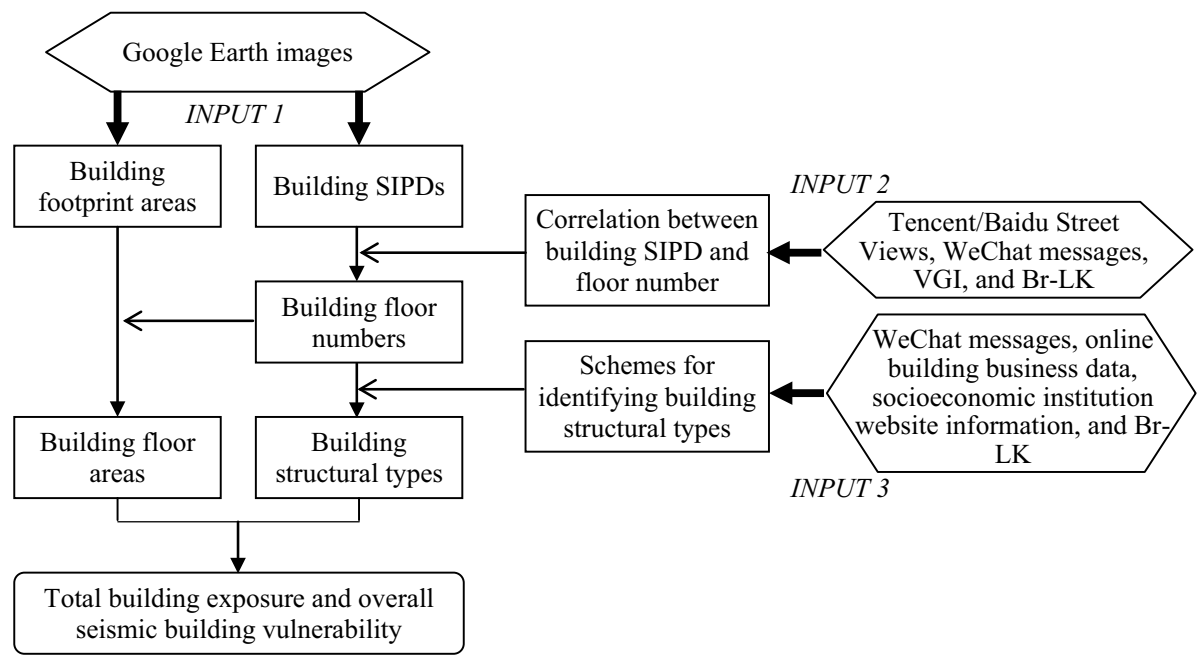

Fig. 2 Overall framework of the proposed "Internet+" approach

and the structural type of each building was identified; based on these information, the total exposure and overall seismic vulnerability property of the addressed buildings in the area were mapped (see Sect. 6).

\subsection{Data and Internet-based systems}

In this "Internet+" approach, four types of data and materials were used: high-resolution GE images, Baidu/Tencent Street Views, Crowdsourcing information and various Br-LK (Table 2).

- High-resolution GE images

The two GE images used were downloaded using GetScreen software (Godeyes 2007). The downloaded GE images are different from commercial ones, such as, lack of imaging geometries and projection information, low spectral resolution. To ensure the associated analysis results obtained in this current study and in our previous one comparable, the two GE images were mosaicked and then registered using the GeoEye-1 images recorded in 2009 that were purchased and used in our previous study (Su et al. 2015). In this registration process, 45 ground control points were used and the overall registration accuracy reached 0.7 pixels.

\section{- Tencent and Baidu Street Views}

Both Tencent and Baidu Street Views are available to the public and free of cost. To date, most prefectural-level cities and above and even some county towns in Mainland China have been covered by one or both the two Street Views. However, most rural areas of the nation have not been covered. In the study area, over $80 \%$ of the main streets and small alleys are currently covered. 


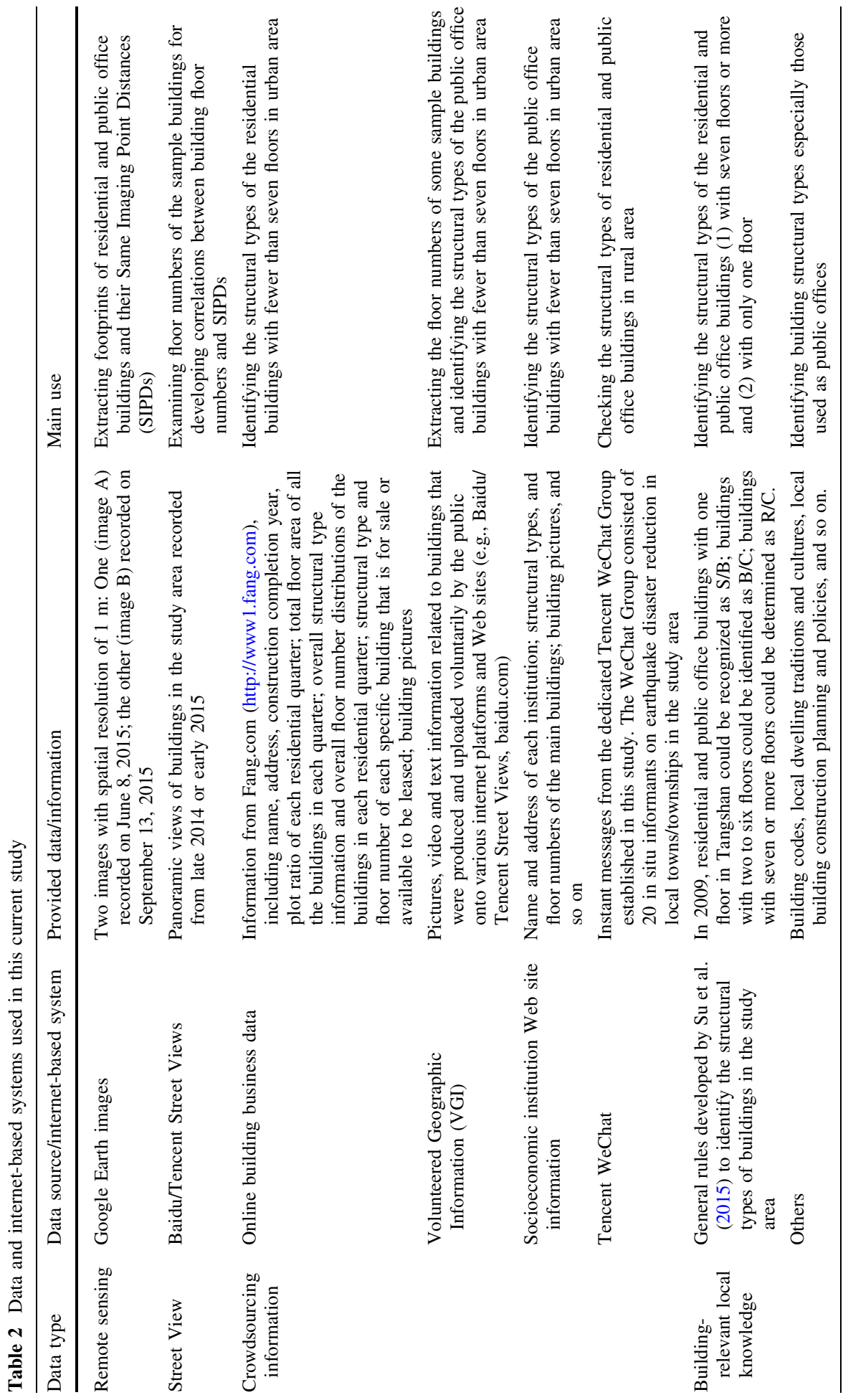


- Local in situ informants on earthquake disaster reduction (abbr. in situ informants)

The in situ informant system is a nation-wide institutional element of the powerful topdown earthquake management system of Mainland China developed by China Earthquake Administration (CEA) in the last decade. Generally, each town or township in Mainland China has at least one in situ informant. The daily responsibilities of them usually include (1) vernacular dwelling construction guidance, (2) (anti-)earthquake disaster knowledge dissemination and education, and (3) seismic activity and disaster information collection and reporting.

- Online building business data

Regarding the current coverage of the online building business information on Mainland China, almost all large- and middle-sized urban built-up areas nationwide and even many county towns in the eastern half of the nation have been covered to a certain extent. In the study area, the information from Fang.com has fully covered all its 532 urban residential quarters.

\section{Estimating building footprint areas from GE images}

To date, experts have developed several automatic and semiautomatic procedures to rapidly delineate roof outlines of buildings from high-resolution optical remote sensing images either with a particular purpose of characterizing earthquake risks (Table 1) or with a wider aim (e.g., Ahmadi et al. 2010; Ghaffarian and Ghaffarian 2014; Gianinetto 2008; Ouzounis et al. 2012; Shorter and Kasparis 2009). However, it remains difficult to apply these technically advanced procedures to irregularly shaped buildings and to identify and eliminate shading, interference, and high gray-tone similarity effects. To improve accuracy, a great deal of post-processing work must be performed. For a large number of buildings, applying these automatic or semiautomatic procedures is more difficult, and sometimes, even impossible (Aytekin et al. 2009; Durieux et al. 2008; Pittore and Wieland 2013; Su et al. 2015; Wieland et al. 2012). The GE images we used have only red, green, and blue bands, i.e., their spectral information is much poorer than that of commercial ones, thereby aggravating such difficulties.

To achieve the level of accuracy that is essential for actual seismic risk reduction practices, this study included manual vectorization to estimate the building footprint areas from the two registered GE images. Using ArcGIS 9.3, the roof outlines of all the residential and public office buildings in the two GE images of the study area in 2015 were manually digitized, and then the footprint areas were estimated accordingly. Indeed, this manual vectorization process was easy and not very time or labor-intensive. For example, all of the densely packed buildings (approximately 1200 individuals) in a $50-\mathrm{km}^{2}$ zone in the study area were well vectorized within $4-5 \mathrm{~h}$ by only one skilled person.

\section{4 "Internet+" approach to the estimation of building floor numbers}

\subsection{Measuring building SIPDs from GE images}

To accurately estimate the total floor area of a building, the number of floors in that building must be reliably determined. For residential or public office buildings, the height 
of a single-floor building and the height of each floor in a multi-floor building are considerably regular and stable in a certain area. In our previous study, we estimated the number of floors in a residential or public office building using a correlation with the height of that building. Considering the quickness, accuracy, and practicability requirements of large-scale exposure, vulnerability, and risk characterizations in a context of rapid socioeconomic growth, we developed in our previous study a new algorithm that requires deriving only one parameter, the "same imaging point distances (SIPDs)," from single high-resolution optical remote sensing image (Hr-ORSI) to rapidly estimate building heights. The SIPD is the distance between the imaging position of a certain point on a building's roof edge and the imaging position of that point's shadow on single Hr-ORSI. The imaging geometry of a building and that of its SIPD are illustrated in Fig. 3; the equations for calculating the building height are presented below ( $\mathrm{Su}$ et al. 2015).

$$
\begin{gathered}
H=L_{\mathrm{sp}} \times \varphi \\
\varphi=\frac{\tan \theta \tan \omega}{\sqrt{\tan ^{2} \theta+\tan ^{2} \omega-2 \tan \theta \tan \omega \cos (\beta-\alpha)}}
\end{gathered}
$$

where $H$ is the building height; $L_{\mathrm{sp}}$ is the SIPD; $\omega$ and $\alpha$ are the elevation and azimuth angles of the relevant satellite, respectively; and $\theta$ and $\beta$ are the elevation and azimuth angles of the sun, respectively.

Unlike commercial images (e.g., the GeoEye-1 images used in our previous study), the two GE images used in the current study do not contain information regarding $\omega, \alpha, \theta$, and $\beta$ in Eq. (2) above. Thus, we cannot obtain building heights from the GE images. However, for a given GE image, these four angles are stable across the entire image, thereby making coefficient $\varphi$ in Eq. (1) above relevant to that image a constant. Because of this constant, it is sure that if a specific stable correlation between the building floor numbers and building heights exists in that image, then a similarly stable correlation between the building floor numbers and building SIPDs also exists. In this current study, we thus determined the floor numbers in a given residential or public office building in the study area using a correlation with the SIPD of that building.

We used ArcGIS 9.3 to manually vectorize the SIPDs of all the addressed buildings from the two GE images used. This task was neither difficult nor particularly time- or labor-consuming. Specifically, the required time and labor was even slightly less than that required by manually digitizing the building footprints. With the SIPDs of all the residential and public office buildings in the study area in 2015 determined, the task left for estimating the floor numbers of these buildings is to establish the correlations between the SIPDs and floor numbers of the buildings.

\subsection{Establishing correlations between building SIPDs and floor numbers}

With the help of GE images, crowdsourcing data, and associated Br-LK, we developed correlations between the SIPDs and floor numbers of the residential and public office buildings in Tangshan through the following steps. The first step was to define two appropriate sets of sample buildings for analysis using a mixed sampling method. Specifically, we first divided all the addressed buildings in the entire study area into two clusters: one corresponding to the buildings covered by GE image A and the other specific to the buildings on GE image B. Because the imaging geometries of the two images may be inherently different, a constant variation may exist between the building SIPDs derived 


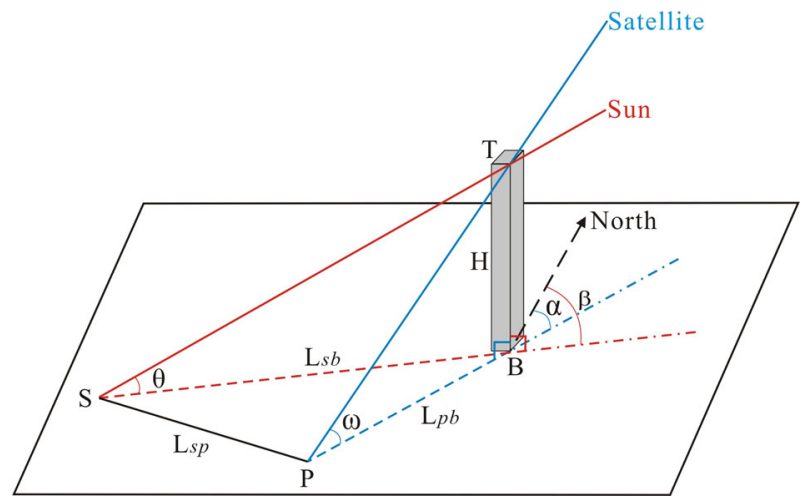

Fig. 3 Imaging geometry of a building and that of its same imaging point distance (SIPD) (Su et al. 2015). Note In this figure, the gray bar represents a building, $T$ denotes a point on the building's roof edge, $B$ is the vertical projection of point $T$ on the ground, $H$ is the building's height, and $P$ and $S$ denote the imaging positions of point $T$ and its shadow, respectively, in a Hr-ORSI. The distance between imaging points $P$ and $S$ is the SIPD, which is denoted by $L_{\mathrm{sp}}$

from GE images A and B. For clarity, we designated the building sample for GE image A as "sample A" and that for image B as "sample B." Second, we determined the sample size for the buildings with each specific number of floors. According to the basic statistical requirements, we decided to select 30 specific sample buildings for the analysis of buildings with each specific floor number (i.e., 30 one-floor buildings, 30 two-floor buildings, 30 three-floor buildings, and so on). Next, we selected the sample buildings specific to each image using a process of stratified sampling. This process was facilitated by extensively referring to associated Br-LK (e.g., building codes, urban planning reports, and our previous study results), and by broadly observing the overall appearances (e.g., heights or high/low-rise appearances) and spatial distributions (e.g., differences between urban and rural buildings or areas) of the addressed buildings in each GE image and in associated Street Views used. Specifically, we first divided the sample buildings specific to each image into two categories, urban buildings and rural ones, and then classified them further into either residential or public office use. Finally, to ensure achieving as reliable SIPD-floor number correlations as possible, we selected the buildings with as clear-cut as possible imaging points for defining SIPDs (points $P$ and $S$ in Fig. 3) as the final sample buildings. The purpose of this last step was to avoid using inaccurately identified and measured SIPDs to determine building floor number-SIPD correlations.

The SIPDs of all the addressed buildings in the study area have been determined in Sect. 4.1, through which we can easily identify those buildings with clear-cut imaging points. Therefore, the key task left was to select those specific sample buildings with a certain number of floors. We used the following three approaches to resolve the issue. (1) We employed Street View from either Baidu or Tencent to check, one by one, the floor numbers of the sample buildings (Fig. 4a) that were currently covered by these two platforms. These sample buildings were mostly selected from urban areas and numbered 663 in total. (2) We entrusted the so-called in situ informants in each local town/township via smart phone-based WeChat Group Chat to check the floor number of each sample building in the locations covered neither by Baidu nor by Tencent Street View and to send us corresponding pictures (Fig. 4b) for our further confirmation. These sample buildings 


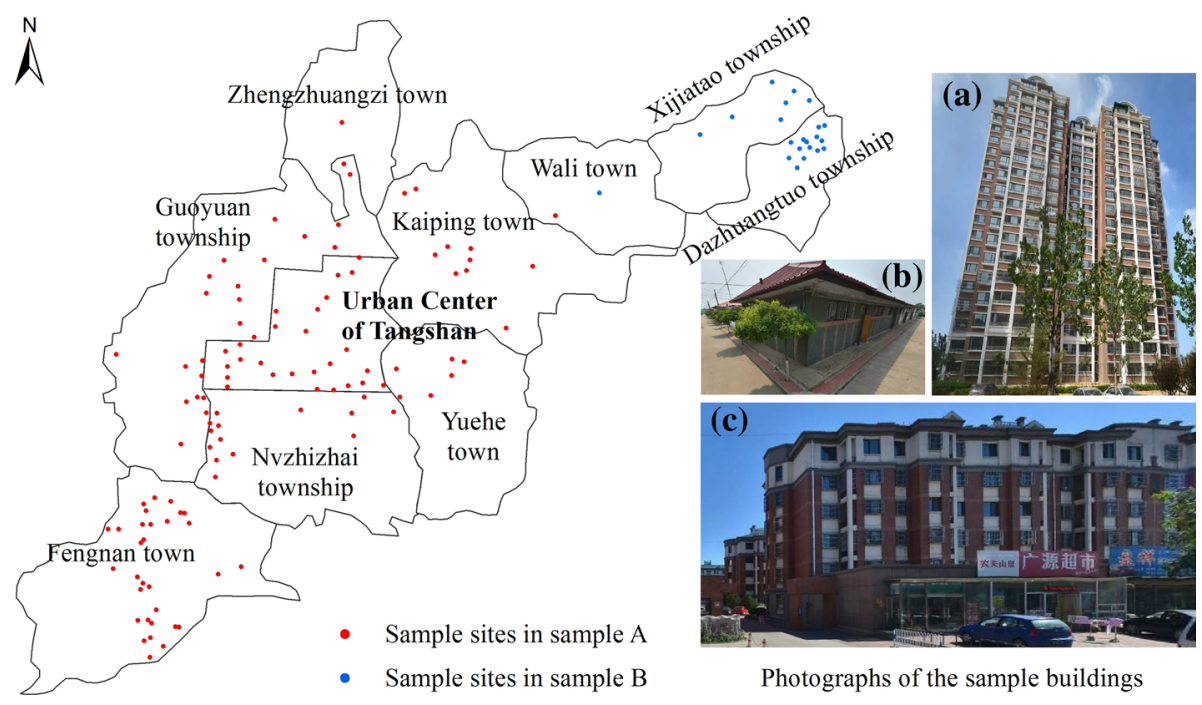

Fig. 4 Locations of the sample sites. Note red dots indicate sample sites in sample A; blue dots correspond to sample sites in sample B. a a piece of Baidu Street View; b a Tencent WeChat picture; $\mathbf{c}$ a VGI picture

were largely located in rural places and totaled 87 in this study case. (3) We used VGI pictures (Fig. 4c) and video and text information as an auxiliary approach. The sample buildings whose floor numbers were confirmed in this way mainly existed in urban areas too, and totaled 19. In so doing, we finally identified 529 sample buildings in total for GE image A (sample A) and 240 for image B (sample B) to determine the correlations between the SIPDs and the floor numbers of the addressed buildings in the study area (Fig. 4). It is worth noting that there were 17-floor and 24-floor buildings whose total numbers were actually less than 30 in the whole part covered by GE image A, so we included all the buildings with these special floor numbers into sample A. Based on these data, we developed correlations between the numbers of floors and the SIPDs of the residential and public office buildings in the study area.

The box plots and the arithmetical means of the SIPD lengths of the sample buildings with different numbers of floors showed that the maximum, minimum, and mean SIPD lengths of the single-floor buildings in sample A were 2.3, 1.8, and $2.0 \mathrm{~m}$, respectively; in sample $B$, the corresponding lengths were $2.1,1.8$, and $1.9 \mathrm{~m}$, respectively. Those of the two-floor buildings in sample A were 4.1, 3.6, and $3.8 \mathrm{~m}$, and in sample B the values were 3.6, 3.3, and $3.5 \mathrm{~m}$, respectively, and so forth (Fig. 5). The fit lines showed that good linear relationships existed between the SIPD lengths and the numbers of floors in both building samples (Fig. 5). These two linear correlations are well defined because the buildings in our study included only those for residential and public office usages.

Thus, we made several general rules as follows to rapidly determine the floor numbers of the residential or public use buildings in Tangshan based on their SIPD lengths on the relevant GE images: buildings covered by GE image A with an estimated SIPD length of approximately 1.8-2.3 m have one floor, those with estimated SIPD lengths of approximately 3.6-4.1 m have two floors, those with estimated SIPD lengths of approximately 5.4-6.2 $\mathrm{m}$ have three floors, and so forth. Similarly, buildings covered by GE image B with 


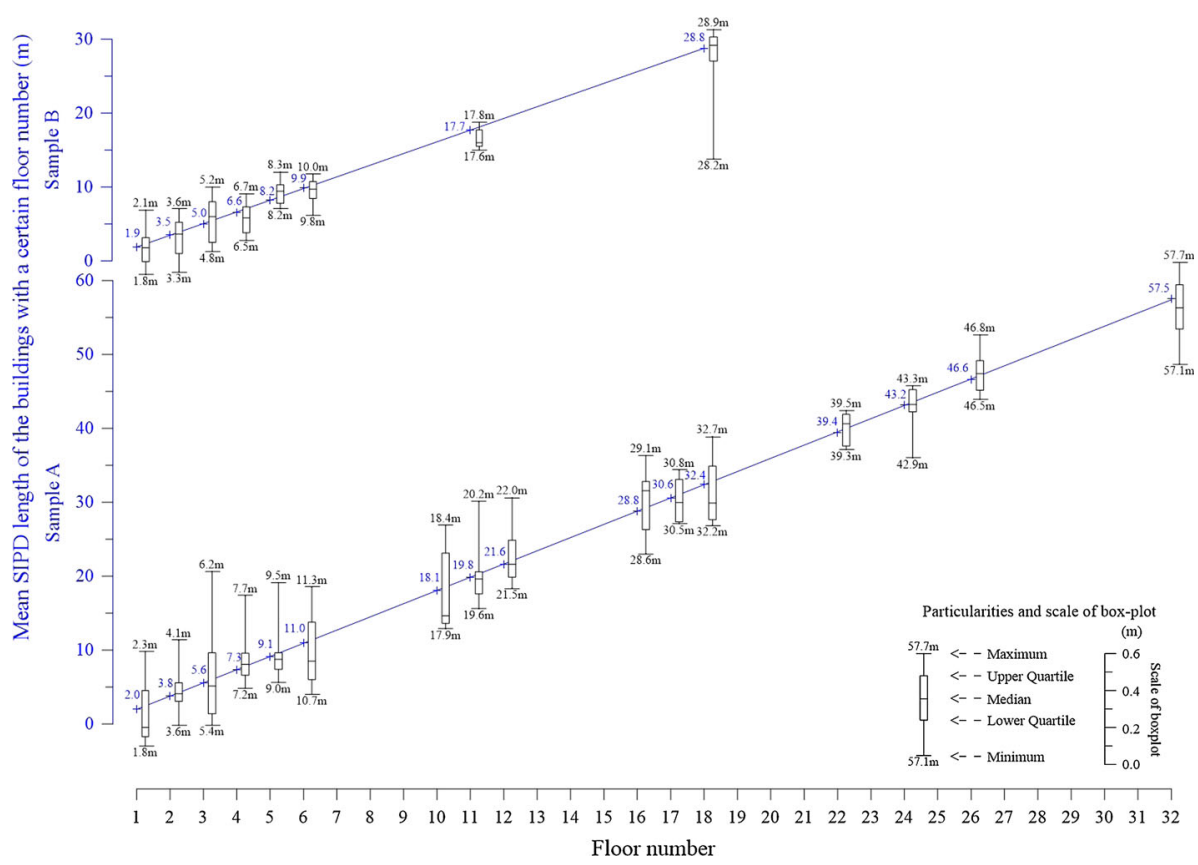

Fig. 5 Box plots and means of the SIPD lengths of the sample buildings in sample A and B with different numbers of floors. Note (1) The figure contains two layers of information that use the same $X$-axis. One layer is the mean SIPD lengths of the buildings with different numbers of floors in sample A and B and is represented by blue crosses indicating mean length points, blue numerals indicating length values, and the blue lines fit to the length points. The other layer is the SIPD length variances of the buildings with different numbers of floors in the two samples, which are illustrated by box plots (in black); (2) All of the box plots are plotted using one length scale (see the lower right of the figure)

estimated SIPD lengths of approximately 1.8-2.1 m have one floor, those with estimated SIPD lengths of approximately 3.3-3.6 m have two floors, those with estimated SIPD lengths of approximately 4.8-5.2 $\mathrm{m}$ have three floors, and so forth. Using these rules and the SIPD lengths that were estimated in Sect. 4.1, the floor numbers were rapidly determined for all of the assessed buildings in Tangshan.

\section{5 "Internet+" approach to the assessment of building structural types}

\subsection{Determining structural types of residential and public office buildings with seven floors or more}

Many studies have used the floor number or height of a building as an input for determining the building structural type (Table 1). This approach was used because the height or floor number of a residential or public office use building in a specific area usually presents a certain empirical correspondence with the structural type of that building. This correspondence is the combined product of various local contexts, including a long tradition of dwelling and architectural cultures, current and historical economic development 
levels, building code requirements, building construction policies, and land use and urban planning practices.

From this standpoint, our previous study concluded that in 2009, (1) residential and public office buildings with one floor in Tangshan could be recognized as S/B, (2) buildings with two to six floors could be identified as B/C, and (3) buildings with seven or more floors could be determined as $\mathrm{R} / \mathrm{C}$ (Su et al. 2015).

Among these correlations, the third is the most stable, because (1) codes for the seismic design of buildings in Mainland China clearly regulate that buildings with more than six floors in zones where the seismic fortification intensity is VIII on the Chinese Seismic Intensity Scale must be of R/C type. Tangshan experienced a terrible Ms 7.8 earthquake in 1976, and intensity VIII specifies exactly the seismic design criterion in this area following this large earthquake, and (2) Tangshan is a relatively industrialized and modernized area in Mainland China, where relevant building codes have been well adhered to since the 1976 earthquake. Currently (in 2015), all the residential and public office buildings with seven floors or more in Tangshan were R/C type. For example, we found in this study that the very few exceptions remaining in 2009 that were very old seven-floor buildings but were B/C type totally disappeared in 2015 .

\subsection{Identifying structural types of residential and public office buildings with one to six floors in urban locations}

As revealed in our previous study, instability in building floor number-structural type relationships in the Tangshan area existed only for the buildings with six or fewer floors (i.e., instability only occurred in the first two general rules mentioned immediately above). The most significant discrepancy was that a considerable number of these relatively short buildings in the study area were R/C type, particularly those for public usage (e.g., schools and hospitals) and those owned by the wealthy families or wealthy institutions. With the rapid economy and income growths and the increasing enhancement of anti-earthquake practices in this area, this inconsistency might be more significant now and in the future. To identify the structure types of these one to six-floor buildings as quickly and reliably as possible, we propose to use "Internet+" tools as the core and Br-LK reviews as the auxiliary to resolve the task. Considering the possible different structural type-floor number correlations between the public and residential and between the urban and rural buildings, particularly considering available internet-based resources and tools in different places in this area, we used different specific "Internet+" methods for the structural type identification of buildings that were located in different places (i.e., urban vs. rural areas) and with different usages (i.e., residential vs. public usages). This sub-section will demonstrate in detail how to identify the structural types of the one to six-floor high residential and public office buildings in the urban locations, while the next sub-section will address the issues of those rural buildings.

\subsubsection{Urban residential buildings}

We used the information from Fang.com to identify the structural types of those urban residential buildings (Table 2). Fang.com provides us with building structural information in the following two ways: (1) overall structural type information of all the buildings in an entire residential quarter of interest. More specifically, the site indicates that all the buildings in an entire given residential quarter were built in one or several specific structural types, for example, in $\mathrm{B} / \mathrm{C}$, in $\mathrm{R} / \mathrm{C}$, or in both of them. However, it does not 
specify in detail which specific building(s) is (are) which specific type(s); (2) detailed information about specific buildings, particularly those buildings that are for sale or available to be leased, including their indoor and outdoor pictures. With such information, experienced building-relevant engineers might easily deduce the structural types of the associated buildings.

Regarding the residential buildings in all the 532 residential quarters in the study area, Fang.com indicated that the buildings in 252 quarters were B/C type, and the buildings in 278 other quarters were R/C type. Thus, we could easily determine the specific structural type of any one of the residential buildings in all these 530 residential quarters. Only two quarters contained buildings with different structural types. We determined the specific structural type of a given building in these two quarters through the following ways. (1) One such quarter was named Tianyuanjunjing. Fang.com indicated that the buildings in it were built either in the $\mathrm{R} / \mathrm{C}$ type or in the $\mathrm{B} / \mathrm{C}$ type. With these summarized messages, we could not clearly determine which buildings are R/C type and which are B/C type. However, Fang.com also informed us that the buildings in this residential quarter were 6 , 11,16 , or 24 floors high. According to the seismic building code in Tangshan, the buildings with 11,16 , or 24 floors must be R/C type; therefore, we concluded easily that the B/C type in this quarter should belong to the buildings with six floors. (2) The other quarter was Xingfuhuayuan, and all the buildings in it were six-floor high. However, Fang.com clearly indicated which buildings were of which specific structural type one by one. In sum, all these buildings were $\mathrm{B} / \mathrm{C}$ type except six buildings that were $\mathrm{R} / \mathrm{C}$ type. From a technical point of view, such building structural type identification processes are easy and quick with the support of increasingly advanced coordinate positioning, location searching and navigation of the associated internet-based platforms.

\subsubsection{Urban public office buildings}

We used information from those socioeconomic institution Web sites and various VGI to determine the structural types of the public office buildings with fewer than seven floors in the urban locations (Table 2). These buildings only numbered 54 in the study area. It is worth emphasizing that VGI is particularly applicable to addressing this type of building, because the public is usually more interested in these buildings than in those residential ones. The results showed that the 49 buildings with six floors or fewer were R/C type, occupying $90.7 \%$ of the total number (54) of these relatively lower buildings. Further analysis showed that these cases (i.e., one to six floors, but not B/C type) largely belong to schools and hospitals. The number of public office buildings is much smaller than that of residential ones. Thus, from a technical point of view, the building structural type identification processes targeting this relatively small number of buildings are also easy and rapid with the support of increasing advances in associated internet-based platforms and technologies.

\subsection{Estimating structural types of residential and public office buildings with one to six floors in rural locations}

Very few buildings in rural locations in Tangshan have been covered by existing online building-relevant information, clues from socioeconomic institution portal Web sites, or evidence contained in VGI. Thus, the approaches demonstrated in Sect. 5.2 that targeted urban residential and public office buildings are not applicable to their rural counterparts. To resolve this issue, we used the following two steps to estimate the structural types of the 
addressed buildings in the rural locations. First, we used the existing Br-LK summarized in our previous study to produce an overall estimate of the structural types of these rural buildings; specifically, the one-floor rural buildings were recognized as S/B type and the two- to six-floor ones were identified as B/C type. Second, we used instant messages provided by our in situ informants through the WeChat Group Chat that was established specially for this current study to check those possible exceptions (Table 2).

From our previous study and associated Br-LK, in rural locations in the study area (in 2009), almost all the residential buildings were one-floor high and of S/B type. While the buildings with two floors or more and with inevitable structural type diversities were nearly all for public usages only (Su et al. 2015). Our exception-checking tasks were thus classified into two categories: (1) identifying possible exceptions in the rural residential buildings village by village (i.e., not in a building by building way). Specifically, we asked our in situ informants through WeChat Group Chat regarding a certain village on the whole if there were residential buildings that were not of S/B type? If there were, how many floors did they contain? Where were they specifically located (by latitude/longitude at best), and what distinct structural features did they have? We also asked them to send us pictures of these exceptional buildings. The geographic scope of each town/township in the study area was not large $\left(17.5-74.2 \mathrm{~km}^{2}\right)$, and each town/township contained only $15-30$ villages. Therefore, this WeChat Group Chat-based checking manner is feasible. The summarization of all the returned instant messages indicated that there were basically no exceptions, i.e., the residential buildings in rural locations in the study in 2015 were almost all one floor and were of S/B type. We admit that this "no exceptions" answer might be not $100 \%$ reliable. But this admission does not necessarily mean that the clearly defined correlation of "one-floor residential buildings correspond to S/B type in rural locations in the study area," will change significantly; because the rural residential buildings in the study area are remarkably consistent in both structural features and visible appearances, and are always significantly clustered regularly together. (2) Identifying the exceptions in the public office buildings in rural areas building by building. In rural locations in Tangshan, the public office buildings include only school structures, buildings of small scale-hospitals, and buildings for grass roots government usages. The number of these buildings was not large, totaling approximately 285 and occupying only $0.5 \%$ of the total number of all the rural buildings in the whole study area. Therefore, entrusting our in situ informants to check the structural types of this small number of buildings one by one is practicable. Our informants conducted these checks through a diverse range of ways: field trips, review of relevant local archives, and asking other persons with associated knowledge. The returned instant information showed that among all the 285 buildings with six floors or fewer, $16.84 \%$ of them were S/B type, all of which were one-floor buildings; $65.96 \%$ were B/C type, most of which were one or two-floor buildings; and $17.19 \%$ were $\mathrm{R} / \mathrm{C}$ type, most of which were two to four-floor buildings (Table 3). These results revealed that many of the one- to six-floor public buildings in rural locations in Tangshan were better structured than the residential ones.

We recognize that the above two checking processes required a bit of time, which largely depended on how rapidly our in situ informants could return the required information. Despite this, these checking processes were actually not particularly time-consuming, i.e., all the checking tasks were completed within one working week. 
Table 3 Numbers and proportions of public office buildings with a certain floor number and structural type in rural locations of the study area

\begin{tabular}{|c|c|c|c|c|c|c|c|}
\hline & One floor & Two floor & Three floor & Four floor & Five floor & Six floor & Total \\
\hline $\mathrm{S} / \mathrm{B}$ & $\begin{array}{l}48 \\
16.84 \%\end{array}$ & 0 & 0 & 0 & 0 & 0 & $\begin{array}{l}48 \\
16.84 \%\end{array}$ \\
\hline $\mathrm{B} / \mathrm{C}$ & $\begin{array}{l}119 \\
41.75 \%\end{array}$ & $\begin{array}{l}60 \\
21.05 \%\end{array}$ & $\begin{array}{l}8 \\
2.81 \%\end{array}$ & $\begin{array}{l}1 \\
0.35 \%\end{array}$ & 0 & 0 & $\begin{array}{l}188 \\
65.96 \%\end{array}$ \\
\hline $\mathrm{R} / \mathrm{C}$ & 0 & $\begin{array}{l}8 \\
2.80 \%\end{array}$ & $\begin{array}{l}26 \\
9.12 \%\end{array}$ & $\begin{array}{l}12 \\
4.21 \%\end{array}$ & $\begin{array}{l}2 \\
0.70 \%\end{array}$ & $\begin{array}{l}1 \\
0.35 \%\end{array}$ & $\begin{array}{l}49 \\
17.19 \%\end{array}$ \\
\hline Total & $\begin{array}{l}167 \\
58.60 \%\end{array}$ & $\begin{array}{l}68 \\
23.90 \%\end{array}$ & $\begin{array}{l}34 \\
11.93 \%\end{array}$ & $\begin{array}{l}13 \\
4.56 \%\end{array}$ & $\begin{array}{l}2 \\
0.70 \%\end{array}$ & $\begin{array}{l}1 \\
0.35 \%\end{array}$ & $\begin{array}{l}285 \\
100.00 \%\end{array}$ \\
\hline
\end{tabular}

\section{Total exposure and overall seismic vulnerability mapping results}

Based on the footprint areas estimated in Sect. 3 and the floor numbers described in Sect. 4, the total floor area of each residential and public office building in 2015 in the study area was calculated. Subsequently, the total floor area of all the buildings with these usages in the entire study area in 2015 was estimated. A comparison of the building stocks in the study area in 2015 and in 2009 indicated that significant growth and changes in building exposures have occurred during this period (Fig. 6). For instance, the total floor area of all the residential and public office buildings in the study area increased from $71,482,089 \mathrm{~m}^{2}$ in 2009 (Su et al. 2015) to $98,494,339 \mathrm{~m}^{2}$ in 2015 , up by $37.79 \%$ (Fig. 6e). In terms of the spatial differences in building exposure growth, the location with the most significant exposure increment was Guoyuan township. From 2009 to 2015, the total floor area of all the residential and public office buildings in Guoyuan township increased by $74.35 \%$ (Fig. 6e).

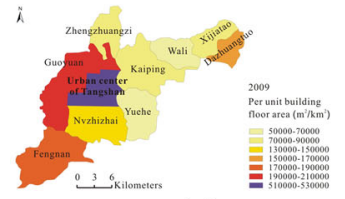

(a)

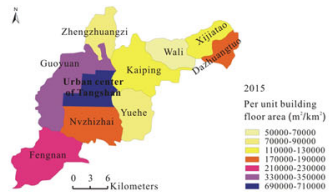

(b)

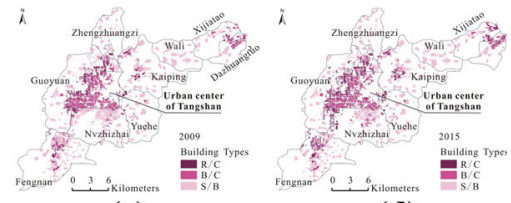

(c) (d)

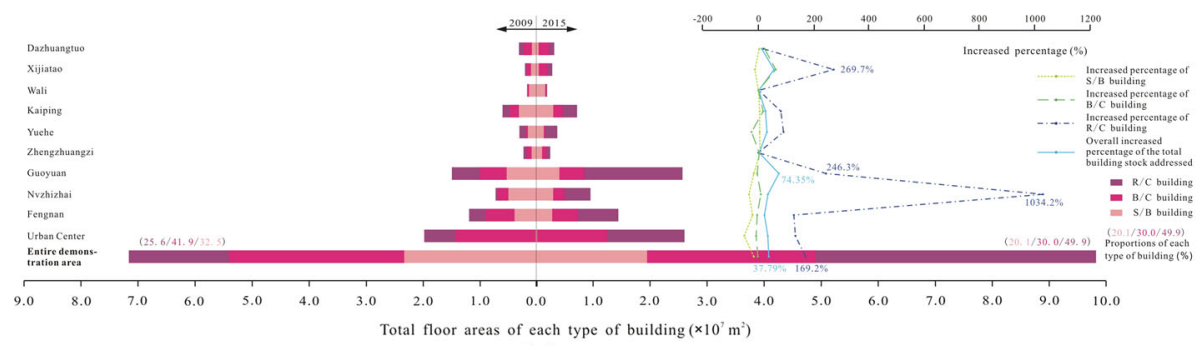

(e)

Fig. 6 Building stock growth and changes in the study area from 2009 to 2015. The per-unit building floor areas in 2009 (a) and in 2015 (b); the distributions of various types of buildings in 2009 (c) and in 2015 (d); building growths by area and type from 2009 to 2015 (e) 
Through the processes described in Sect. 5, the structural types of all of the residential and public buildings in the study area in 2015 were carefully identified. The results showed that the buildings with relatively good anti-seismic performance in 2015 , including the R/C and $\mathrm{B} / \mathrm{C}$ buildings, were primarily distributed in the urban center, western urban outskirts, and at a few additional locations (including north of the towns of Fengnan and Dazhuangtuo); while the S/B buildings were distributed across the rural and suburban regions (Fig. 6d). This distribution pattern indicated large structural vulnerability variations from place to place. The most structurally resilient area in 2015 was the urban center, in which few S/B buildings existed; the most seismically vulnerable location was Wali town, in which few R/C buildings existed (Fig. 6d). A broad comparative observation of the building distributions in 2015 (Fig. 6d) and in 2009 (Fig. 6c) indicated that the overall spatial distribution pattern of the structural vulnerability in the study area has not changed substantially from 2009 to 2015 .

Based on the total floor area of each building and its structural type, we rapidly obtained the overall total floor areas of each type of building ( $\mathrm{S} / \mathrm{B}, \mathrm{B} / \mathrm{C}$, and $\mathrm{R} / \mathrm{C}$ buildings) within the entire study area in 2015 (see bars in Fig. 6e). A comparison of the overall structural type composition structures (i.e., floor area percentage of each type of buildings) in the whole building stock in the study area in 2009 and in 2015 indicated that significant structural resilience strengthening has occurred in the last few years. For example, as the overall floor area proportions of both $\mathrm{S} / \mathrm{B}$ and $\mathrm{B} / \mathrm{C}$ buildings substantially decreased, the proportion of $\mathrm{R} / \mathrm{C}$ buildings has grown from $25.6 \%$ in 2009 to $49.9 \%$ in 2015 in the whole residential and public building stock of the study area. This significant improvement in the anti-seismic performance of buildings in this study area is a result of the policy of "Great changes within three years" of Tangshan that was advocated by the government of Hebei Province, China, since 2008 (Hebei Daily 2010). As with rapid socioeconomic development, particularly predictable rapid urban expansions, this structural resilience enhancing trend might be increasingly significant in the future.

\section{Verifications}

From previous sections, the overall reliability and accuracy of the proposed "Internet +" approach to mapping the exposure and seismic vulnerability of buildings developed in this study essentially depends on the following: (1) the accuracy of the estimated building footprint areas from the GE images, (2) the reliability of the estimated correlations between the building SIPDs and floor numbers, and (3) the reliability of the identified building structural types. To test these accuracies and reliabilities, a careful field sampling investigation was conducted.

The top priority of this field investigation was to select an adequate group of sample buildings. We determined our selection of sample buildings after a systematic consideration of the factors as follows: (1) image factors that affected the clear identification and accurate measurement of building roof outlines (relevant to building footprints) and SIPDs (relevant to building floor numbers) in the GE images with a spatial resolution of $1 \mathrm{~m}$ and only red, green, and blue bands. The details of how these factors might affect building exposure estimates and the corresponding specific sampling process have been discussed at length in our previous study (Su et al. 2015); (2) adequate representatives of the individual buildings whose structural types were determined in this current study in groups (i.e., in a residential quarter by residential quarter, institution by institution or village by village 
manner, not building by building) using the information provided by Fang.com, institution portal Web sites, or our specialized WeChat Group Chat; (3) representativeness of the sample buildings that could properly cover the urban versus rural and the public office versus residential use differences in structural types of the buildings with a same number of floors. These two types of representativeness all focused on building structural type aspect and actually overlapped heavily with each other. Specifically, the buildings covered by the information from Fang.com were those for urban residential use, institution portal Web sites provided data for the public office buildings, and the dedicated WeChat message platform in this study addressed those rural buildings. Thus, it was reasonable and possible to consider the two types of representativeness together when selecting specific sample buildings; and (4) reliability of the clues provided by various internet-based platforms used. This reliability aspect essentially depends on either the service quality of associated building-focused or relevant Web sites or on the willingness, responsibility, and buildingfocused knowledge levels of our in situ informants. This fourth factor might significantly affect the correct identification of building structural types and thus was particularly valued in selecting sample buildings.

Based on all of these considerations, we selected two separate sets of sample buildings to approach our verification task. The first set was to address image factors and test building exposure estimation accuracies determined by them; we designated this as the "exposure test sample." We identified this building sample based on an old sample of buildings (totaling 954) that had been carefully selected in our previous study using a mixed sampling approach (Su et al. 2015). From 2009 to 2015, most buildings (totaling 856) in this old sample have remained unchanged; to make full use of our previous work, we thus decided to retain these buildings to still serve as the sample buildings in this current study. There were 98 buildings in total which either changed or disappeared during this period. We therefore used the buildings in locations near these old sample sites and with a similar extent of associated image interference and shading, and irregular building shape effects to replace these changed or disappeared buildings. The sample buildings in this updated sample (the exposure test sample) still came from the following three types of sample sites: low effect site, moderate site, and high-effect sites, which still measured 2, 3.6 , and $1 \mathrm{~km}^{2}$, respectively. In so doing, we finally collected a building sample (i.e., the exposure test sample) that contained 971 individual buildings in this current study to test the accuracy of our "Internet+"-based building exposure assessments.

Our second set of sample buildings was selected to test the reliability of the identification of structural types and was designated simply as the "structural type test sample." The key task in delineating this sample was selecting the individual sample buildings whose structural types were synoptically recognized in the group using Fang.com, institution portal Web sites, and the WeChat platform. (1) In urban areas, we firstly selected residential quarters or socioeconomic institutions with buildings having six floors or fewer as our sample residential quarters or sample socioeconomic institutions by cluster sampling, because local building codes clearly regulate that the residential and public office buildings in this area with seven or more floors must be of R/C type. Then, within each sample quarter or institution, we used stratified sampling to select one or two buildings from all the buildings with a certain same number of floors less than or equal to six to serve as our final sampling buildings. In other words, from the three-floor buildings, we selected one or two individuals into our sample; from the four-floor buildings, we selected one or two; and so on. (2) In rural areas, we focused our structural type test sample buildings primarily on those for public usages, because, from Br-LK of the study area, the rural residential buildings in the area were almost all of S/B type, whereas almost all of the 
structural type variations occurred in the public office buildings only. Such a sample building selection was also based on cluster sampling, with an important and particular aim of examining how willing, responsible, and knowledgeable our in situ informants were when handling this additional task, which was not part of their normal daily work. The number of public office buildings in rural locations was not large. Thus, considering our aims to understand the structural type variations in these public buildings as thoroughly as possible, and keeping in mind to evaluate the willingness, responsibility, and buildingrelevant knowledge levels of our in situ informants, we designated all of the 285 public buildings in rural part of the whole study area as our final sample buildings. (3) To make full use of the associated work in our previous study and to cover the possible structural type versus floor number correlation exceptions in rural residential buildings, we also fed all the 155 one- to six-floor buildings out of the total 235 old sample buildings (all of them remaining unchanged from 2009 to 2015) used in our previous study (Su et al. 2015) into our final second building sample: the structural type test sample. These old sample buildings, which well covered rural residential buildings, had previously been used to develop the general correlations between the building height and number of floors and between the number of floors and structural types in our previous study. Through the three sampling processes above, we finally included 1016 individual sample buildings in total to test the reliability of our "Internet+" based building structural type identification methods proposed in this study. Obviously, these sampling processes addressed simultaneously both the possible urban versus rural and public office versus residential use differences in their structural types of the buildings with a certain number of floors.

After the development of these two building samples above, the next step was to collect required data in the field. The specific work included: (1) targeting the sample buildings that were newly selected in this current study (totaling 115) for the first sample set (addressing various image factors), to collect the complementary data for the accuracy assessments of building footprint and floor number estimates. For this task, we used a handheld laser rangefinder to measure the true footprint areas of these new sample buildings and used a handheld GPS to locate their exact spatial positions and record their numbers of floors. Next, we integrated these new data with the same type of data of those unchanged old sample buildings (from 2009 to 2015) collected in our previous study to form a complete data set with respect to the first set of sample buildings. (2) For the second set of sample buildings that focused on the issue of building structural type identification, we used a handheld GPS to record their floor numbers and structural types and locate their exact spatial positions. All the field investigations above cost 3 skilled persons 3 days in total.

With these field investigation data, the accuracy and reliability of the proposed "Internet+" approach to mapping building exposures and characterizing their seismic vulnerabilities was then evaluated.

\subsection{Accuracy of the estimation of building footprint areas}

After comparing the true footprint areas of the sample buildings in the exposure test sample measured in the field with the footprint areas estimated using the proposed method, we concluded that the overall accuracies of the estimated footprint areas of the buildings were satisfactory (Figs. 7, 8; Table 4). Overall, a good linear relationship was observed between the measured footprints obtained in the field and the estimated footprints derived from the GE images (Fig. 7). The average measured footprint area of the sample buildings was $625.60 \mathrm{~m}^{2}$, and the average estimated footprint area was $627.38 \mathrm{~m}^{2}$. The mean absolute 
error (MAE) between these measured and estimated areas was $16.84 \mathrm{~m}^{2}$, and the mean absolute percentage error (MAPE) was 3.01\% (Table 4). Concerning the differences between the measured and estimated areas of each individual sample building, the buildings that had relative differences of less than $3.01 \%$ accounted for $63.23 \%$ of the total sample buildings. Only 45 buildings had relative differences that exceeded $10 \%$, which accounted for $4.63 \%$ of all of the sample buildings (Table 4). The larger errors nearly all occurred at the moderate and high-effect sites (Table 4; Fig. 8).

\subsection{Reliability of the determination of the building floor numbers}

The field investigation data in the exposure test sample could also serve to test the accuracy of the building floor number estimates using the proposed "Internet+" approach. After comparing the floor numbers of the sample buildings ascertained using their correlations with SIPDs to the actual floor numbers recorded in the field, it was found that the proposed "Internet+" approach to floor number estimation was of good accuracy. The confusion matrix showed that the overall agreement between the estimated floor numbers and the actual floor numbers was $88.98 \%$, with a kappa coefficient of 0.86 (Table 5). This agreement was slightly lower than that (91.61\%, with kappa coefficient 0.89$)$ of using commercial GeoEye-1 images in our previous study (Su et al. 2015). The cause is most likely that the spatial resolution of the GE images (i.e., $1 \mathrm{~m}$ ) used in this study is slightly lower than that of the commercial GeoEye-1 images (i.e., $0.41 \mathrm{~m}$ ) used in the previous study.

Based on the actual floor areas of the sample buildings measured in the field, we also easily calculated that the overall MAPE of the proposed "Internet+" approach in assessing the total floor area of the addressed buildings was $4.64 \%$. With the good accuracies of all the estimates of building footprints, floor numbers, and floor areas, we concluded that our "Internet+" approach to the estimation of the total building exposures was accurate and reliable.

\subsection{Reliability of the identification of building structural types}

According to the seismic building code in the Tangshan area, structural type uncertainties in the residential and public office buildings in this area only occurred among those buildings with one to six floors. We thus carefully developed a particular building sample named the "structural type test sample" to evaluate the reliability of our "Internet+" approaches to the assessment of the structural types of those one to six-floor residential and public buildings. The field investigation data of the sample showed that $31.44 \%$ of the single-floor sample buildings were S/B type, and $68.56 \%$ were B/C type; $72.14 \%$ of the sample buildings with two to six floors were B/C type, and $27.86 \%$ were $\mathrm{R} / \mathrm{C}$ type. By systematically comparing these actual structural types recorded during the field investigations with those identified using our "Internet+" approach, we concluded that our new method was of very good reliability in identifying the structural types of the residential and public office buildings with one to six floors in the study area. The associated confusion matrix showed that the overall agreement between our "Internet+"-based rapid estimates and the corresponding realities could reach $97.54 \%$, with a kappa coefficient of 0.94 (Table 6). 


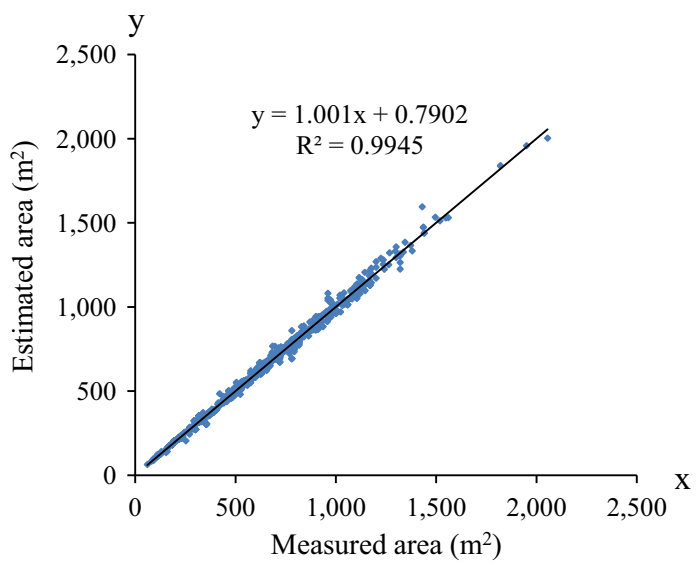

Fig. 7 Scatter plot of the estimated and measured building footprint areas

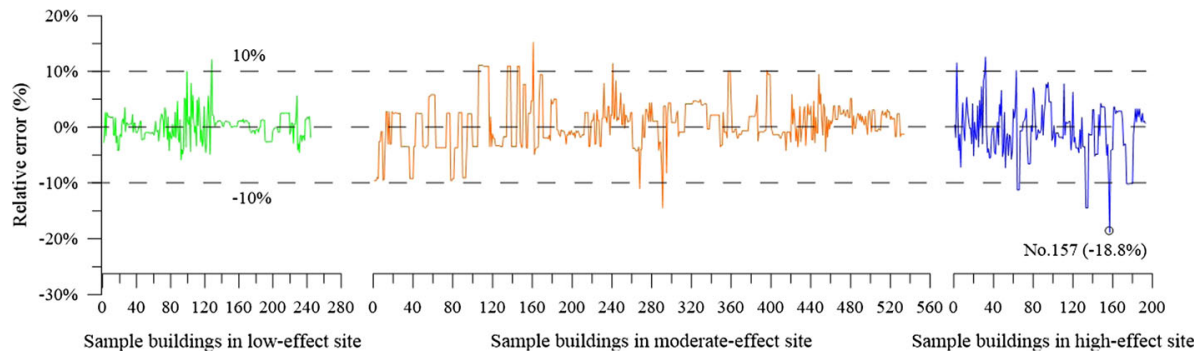

Fig. 8 Relative differences between the measured and estimated footprint areas of the sample buildings. Note (1) On all $x$-axes, the sample buildings at each effect site were arranged by footprint size, with larger (serial) numbers of buildings corresponding with larger building footprint areas; (2) relative errors were obtained by subtracting the measured footprint areas from their estimated footprints

Table 4 Summary of the building footprint area estimation errors

\begin{tabular}{|c|c|c|c|c|c|c|c|}
\hline \multirow[t]{2}{*}{ Sample buildings } & \multirow[t]{2}{*}{ MAE } & \multirow[t]{2}{*}{$\begin{array}{l}\text { MAPE } \\
(\%)\end{array}$} & \multirow[t]{2}{*}{$r$} & \multirow[t]{2}{*}{ RMSE } & \multirow[t]{2}{*}{$\begin{array}{l}\text { Total number of } \\
\text { buildings }\end{array}$} & \multicolumn{2}{|c|}{$\begin{array}{l}\text { Buildings with relative } \\
\text { errors exceeding } 10 \%\end{array}$} \\
\hline & & & & & & Number & $\begin{array}{l}\text { Percentage } \\
(\%)\end{array}$ \\
\hline Entire sample & 16.84 & 3.01 & 0.997 & 22.87 & 971 & 45 & 4.63 \\
\hline Low effect site & 13.99 & 1.78 & 0.997 & 19.35 & 244 & 2 & 0.82 \\
\hline $\begin{array}{l}\text { Moderate effect } \\
\text { site }\end{array}$ & 16.27 & 3.27 & 0.998 & 19.88 & 534 & 26 & 4.87 \\
\hline High-effect site & 22.02 & 3.77 & 0.996 & 32.63 & 193 & 17 & 8.81 \\
\hline
\end{tabular}

$M A E$ mean absolute error, MAPE mean absolute percentage error, $r$ Pearson's product-moment correlation coefficient, $R M S E$ root mean square error 
Table 5 Summary of the confusion matrix between the actual floor numbers of the sample buildings and those estimated using the "Internet+" approach proposed in this study

\begin{tabular}{|c|c|c|c|c|c|c|c|c|c|c|c|c|}
\hline Actual number of floors & 1 & 2 & 3 & 4 & 5 & 6 & 7 & 8 & 9 & 10 & 11 & 12 \\
\hline $\begin{array}{l}\text { Total number of buildings with certain } \\
\text { numbers of floors }\end{array}$ & 20 & 19 & 59 & 37 & 246 & 337 & 14 & 11 & 6 & 11 & 36 & 14 \\
\hline $\begin{array}{l}\text { Number of buildings with correct floor } \\
\text { estimations }\end{array}$ & 20 & 19 & 54 & 34 & 225 & 318 & 13 & 11 & 4 & 9 & 25 & 10 \\
\hline $\begin{array}{l}\text { Number of buildings over-estimated by one } \\
\text { floor }\end{array}$ & & & 5 & & 2 & 3 & 1 & & & 2 & & 1 \\
\hline $\begin{array}{l}\text { Number of buildings under-estimated by } \\
\text { one floor }\end{array}$ & & & & 3 & 19 & 16 & & & 2 & & 5 & 3 \\
\hline \multicolumn{13}{|l|}{$\begin{array}{l}\text { Number of buildings with other estimation } \\
\text { errors }\end{array}$} \\
\hline Actual number of floors & 13 & 14 & 15 & 16 & 17 & 18 & 21 & 22 & 25 & 26 & 28 & \\
\hline $\begin{array}{l}\text { Total number of buildings with certain } \\
\text { numbers of floors }\end{array}$ & 1 & 2 & 8 & 19 & 34 & 37 & 13 & 12 & 4 & 13 & 18 & \\
\hline $\begin{array}{l}\text { Number of buildings with correct floor } \\
\text { estimations }\end{array}$ & 1 & 2 & 6 & 10 & 26 & 29 & 9 & 11 & 3 & 11 & 14 & \\
\hline $\begin{array}{l}\text { Number of buildings over-estimated by } \\
\text { one floor }\end{array}$ & & & & 7 & 3 & 2 & & & & & & \\
\hline $\begin{array}{l}\text { Number of buildings under-estimated by one } \\
\text { floor }\end{array}$ & & & 2 & 2 & 5 & 5 & 4 & 1 & 1 & 2 & 4 & \\
\hline $\begin{array}{l}\text { Number of buildings with other estimation } \\
\text { errors }\end{array}$ & & & & & & $1^{\mathrm{a}}$ & & & & & & \\
\hline
\end{tabular}

Overall accuracy: $88.98 \%$, kappa coefficient: 0.86

a All errors resulted from misestimating one floor, except for one 18-floor building at the high-effect site that was incorrectly estimated to have 15 floors

\section{Discussion and final remarks}

Rapid socioeconomic growth in an earthquake-prone area can cause rapid exposure, vulnerability and seismic loss risk changes. These changes challenge seismic disaster risk reduction strategies in the area, which must be updated in a timely fashion to remain realistic and effective over time. The top priority for overcoming these difficulties is to map the ongoing rapid exposure and vulnerability changes in a timely and accurate manner. However, the methods for rapidly and accurately characterizing such changes over a large area have been insufficiently explored. Building on the basic logic of our previous method (Su et al. 2015), this current study developed an "Internet+" approach to continue grappling with this issue. As promising "Internet+" strategy develops more extensively and with increasingly rapid advances of associated underlying internet and modern information technologies, this "Internet+" approach to mapping building exposures and seismic vulnerabilities might play a highly useful role in the pressing seismic loss risk reduction fields of earthquake-active areas in which socioeconomic growth and city expansion are rapid.

By focusing on residential and public office buildings, the proposed "Internet+" approach begins with employing either the new method developed in our previous study (Su et al. 2015) or the old but actual practice-favorable manual method to accurately and quickly extract SIPDs and footprint areas of a large number of buildings from high- 
Table 6 Confusion matrix between the actual structure types of the sample buildings and those identified using the "Internet+" approach proposed in this study

\begin{tabular}{|c|c|c|c|}
\hline $\begin{array}{l}\text { Numb } \\
\text { estim } \\
\text { "Inte }\end{array}$ & $\begin{array}{l}\text { build } \\
\text { ructu } \\
\text { app }\end{array}$ & \multirow[t]{2}{*}{$\begin{array}{l}\text { Total } \\
\text { building } \\
\text { number }\end{array}$} & \multirow{2}{*}{$\begin{array}{l}\text { User accuracy (Correctly } \\
\text { estimated percentage of } \\
\text { buildings with each actual } \\
\text { structural type using } \\
\text { "Internet+" approach) (\%) }\end{array}$} \\
\hline & $\mathrm{B} / \mathrm{C}$ & & \\
\hline
\end{tabular}

\begin{tabular}{lcccrr} 
Number of buildings with each actual structure type & & \\
S/B & 59 & 2 & 0 & 61 & $96.72 \%$ \\
B/C & 15 & 710 & 1 & 726 & $97.80 \%$ \\
R/C & 0 & 7 & 222 & 229 & $96.94 \%$ \\
Total building number & 74 & 719 & 223 & 1016 & \\
Produce accuracy (Correct & $79.73 \%$ & $98.75 \%$ & $99.55 \%$ & & \\
percentage of "Internet+" & & & & & \\
approach to estimate the \\
structural types of \\
buildings) (\%) \\
Overall accuracy: $97.54 \%$, kappa coefficient: 0.94 \\
\hline
\end{tabular}

resolution GE images. Based on these two initial parameters, this "Internet+" approach introduces an integrated use of Tencent/Baidu Street Views, WeChat-based in situ messages, and building-relevant VGI to quickly estimate floor numbers and then the total floor areas of these buildings. After this, the proposed "Internet+" approach achieves the rapid identification of the structural types of this large number of buildings through a combined use of online building business data, building information on socioeconomic institution portal Web sites, WeChat-based in situ messages and associated Br-LKs. In so doing, the building exposure and seismic structural type examination processes in conventional LRC or DPM-based earthquake loss estimates are all properly replaced. Thus, the timeliness and accuracy are all satisfactorily ensured when estimating building exposures and vulnerabilities across large areas with rapid socioeconomic development.

The proposed "Internet+" approach was demonstrated in Tangshan, China, an area that experienced the severe effects of Ms 7.8 earthquake in 1976 and that has experienced significant expansion of the population, economy, and urbanization since that event. Our field-based verification indicated that the mean absolute percentage error (MAPE) of our "Internet+" approach (used GE images) for estimating the footprint areas of the assessed buildings was $3.01 \%$; the overall agreement between the estimated floor numbers using this "Internet+" approach and the actual floor numbers of the addressed buildings was $88.98 \%$, with a kappa coefficient of 0.86 ; the overall MAPE of the proposed "Internet+" approach in assessing the total floor area of the addressed buildings was $4.64 \%$. The overall consistency between the "Internet+" approach-based estimates of the structural types of the one to six-floor residential and public buildings among which structural type uncertainties occurred only and their actual structural types could reach $97.54 \%$, with a kappa coefficient of 0.94. Apart from its good accuracy, this "Internet+" approach also presents the following advantages relative to conventional LRC and/or DPM-based building exposure and seismic vulnerability analysis methods: (1) noteworthy speed-after the high-resolution GE images were prepared and our in situ informant group was established, the building exposure and seismic structural type estimates targeting the study area measuring $456 \mathrm{~km}^{2}$ and containing densely packed buildings were completed in 
approximately ten working days by two skilled individuals; (2) substantial labor savings which mainly results from avoiding those heavy field work in preparing building inventories associated with conventional earthquake loss estimation methods; (3) negligible cost and easy coverage of large areas (in financial sense), because the proposed approach is built on an integrated use of the building information either contained in various internetbased open platforms on which relevant services and information are usually available at no cost to the public, or provided free by the public (e.g., VGI) or by our specialized volunteers (i.e., our in situ informants); and (4) being favorable to capture the most up-todate situations of one's concerns which is a combined product of the up-to-date and/or near real time information from Google Earth, Baidu/Tencent Street Views, and various crowdsourcing manners (including our Wechat-based in situ messages). In addition to these obvious advantages, the proposed "Internet+" approach also has several highly predictable and particularly attractive prospects in mapping building exposures and seismic vulnerabilities and risks: (1) it might offer an increasingly higher level of services in the future (i.e., more detailed, rapid and accurate, on a much larger scale, and more easily updated) driven either by the increasingly rapid advances of various internet and modern information technology-based resources or tools, or by the fast development of other relevant emerging fields (e.g., Big Data, Cloud Computing and similar). (2) It might become increasingly applicable and transferable worldwide due to the rapid development of these underlying resources, tools and associated new technology fields. (3) It might be capable of engaging increasingly extensively, intensively, and sustainably with the grass roots (e.g., in situ informants in this study) and the public (e.g., through VGI) in seismic disaster risk characterization researches and governance practices. The development of the grass roots and the public participation in disaster risk reduction fields has been far from sufficient in many societies of the world.

A comparison of the estimated exposures and identified seismic structural types of the residential and public office buildings in central Tangshan, between this current study and our previous attempt (Su et al. 2015), showed that the total floor area of the addressed buildings in this area in 2015 was $37.79 \%$ more than the corresponding number in 2009 . This result clearly showed that the building exposure in this seismic active area with a booming economy has been continuing to increase considerably in the past few years. Fortunately, this comparison also showed that the structural type composition patterns (herein referred to as the floor area percentage of each type of building) in the entire residential and public office building stock in this seismic active area have changed even more significantly. That is, the floor area percentage of the $\mathrm{R} / \mathrm{C}$ buildings has increased from $25.6 \%$ in 2009 to $49.9 \%$ in 2015, whereas that of S/B buildings has decreased from $32.5 \%$ to $20.1 \%$. These changes clearly demonstrated that significant improvement in anti-seismic performance in the residential and public office buildings in this area has also occurred in this very recent period. These significant exposure and vulnerability changes in so short a period convincingly reiterated the significant necessity and challenges of timely and accurate capture and then properly coping with those rapid changing hidden problems in an earthquake-prone area with rapid socioeconomic growth and urbanization expansion.

The timely and accurate large-scale mapping of seismic exposures, vulnerabilities and loss risks and their change scenarios in areas with rapid socioeconomic growth is a work that involves many challenges. This "Internet+" approach was developed based on a flat area with a relatively developed socio-economy and a relatively advanced internet and modern information and communication infrastructure in Mainland China. And it focused on residential and public office buildings only. Applying the general ideas and overall guidelines provided by this "Internet+" approach to a mountainous or hilly region, to 
specially structured buildings (and other seismic impact-susceptible human objects), or to other locations either within or outside of Mainland China might face many specific uncertainties. These uncertainties might be defined either by local contexts (e.g., availabilities of required internet and modern information-based resources and tools), by the specific seismic impact-susceptible objects of one's interest (e.g., transportation system), or by both of these factors. However, as promising "Internet+" strategy and the associated underlying internet and modern information technologies develop growingly rapidly world-wide, and as seismic loss risk reduction in earthquake-active areas with rapid socioeconomic growth becomes increasingly pressing, understanding the exact nature of these uncertainties specific to a particular area or to a particular other kind of seismic impact-susceptible human object, and then to determine which of these challenges can be resolved, to what degree they can be resolved and the ways in which they can be resolved through a local context- or targeting human object-specific "Internet+" approach is becoming an increasingly attractive and worthwhile area for research.

Acknowledgments This research was supported by a project (its National Natural Science Foundation of China Grant No. is 41661134013) belonging to an UK-China Collaboration programme "Increasing Resilience to Natural Hazards in Earthquake-Prone regions in China." The programme was jointly funded by the Natural Environment Research Council and the Economic and Social Research Council of the UK, and by the National Natural Science Foundation of China. This research was also supported by another project of the National Natural Science Foundation of China (Grant No. 40971274). We extend our sincere thanks to the 20 in situ informants on earthquake disaster reduction in the area of Tangshan, for providing us with associated WeChat Group Chat-based instant messages on local buildings. Special thanks are due to Google for its freely available images for research purpose. We also sincerely thank the anonymous reviewers and associated editors for their constructive and detailed comments and suggestions during the preparation of the paper.

Open Access This article is distributed under the terms of the Creative Commons Attribution 4.0 International License (http://creativecommons.org/licenses/by/4.0/), which permits unrestricted use, distribution, and reproduction in any medium, provided you give appropriate credit to the original author(s) and the source, provide a link to the Creative Commons license, and indicate if changes were made.

\section{References}

Agnew DC (2009) Upside-down quakes: displaying 3D seismicity with Google Earth. Seismol Res Lett 80(3):499-505. doi:10.1785/gssrl.80.3.499

Ahmadi S, Zoej M, Ebadi H, Moghaddam H, Mohammadzadeh A (2010) Automatic urban building boundary extraction from high resolution aerial images using an innovative model of active contours. Int J Appl Earth Obs Geoinf 12(3):150-157. doi:10.1016/j.jag.2010.02.001

ATC (Applied Technology Council) (1985) ATC-13-Earthquake damage evaluation data for California. http://www.atcouncil.org/pdfs/atc13.pdf. Accessed 15 Sept 2009

Aytekin O, Ulusoy I, Erener A, Duzgun HSB (2009) Automatic and unsupervised building extraction in complex urban environments from multi spectral satellite imagery. 4th international conference on recent advances in space technologies, 2009. IEEE, Istanbul, pp 287-291

Borfecchia F, Pollino M, De Cecco L, Lugari A, Martini S, La Porta L, Ristoratore E, Pascale C (2010) Active and passive remote sensing for supporting the evaluation of the urban seismic vulnerability. Ital J Remote Sens 42(3):129-141

Carreño M, Cardona O, Barbat A (2007) A disaster risk management performance index. Nat Hazards 41(1):1-20

Chen Q, Jiang LX, Shuai XH (2008) The application of Google Earth in earthquake emergency. Earthquake 28(1):121-128 (in Chinese with English abstract)

Costanzo D, Cappadonia C, Conoscenti C, Rotigliano E (2012) Exporting a Google Earth ${ }^{\mathrm{TM}}$ aided earthflow susceptibility model: a test in central Sicily. Nat Hazards 61:103-114 
Costanzo A, Montuori A, Silva J, Silvestri M, Musacchio M, Doumaz F, Stramondo S, Buongiorno M (2016) The combined use of airbrone remote sensing techniques within a GIS environment for the seismic vulnerability assessment of urban areas: a operational application. Remote Sens 8(2):146. doi: $10.3390 /$ rs 8020146

Cutter S, Finch C (2008) Temporal and spatial changes in social vulnerability to natural hazards. Proc Natl Acad Sci USA 105(7):2301-2306

Cutter S, Boruff B, Shirley W (2003) Social vulnerability to environmental hazards. Social Sci Q 84(2):242-261

De Longueville B, Luraschi G, Smits P, Peedell S, De Groeve T (2010) Citiezens as sensors for natural hazards: a VGI integration workflow. Geomatica 64(1):41-59

Dell'Acqua F, Gamba P, Jaiswal K (2013) Spatial aspects of building and population exposure data and their implicaitons for global earthquake exposure modeling. Nat Hazards 68(3):1291-1309

Dufty N (2012) Using social media to build community disaster resilience. Aust J Emerg Manag 27(1):40-45

Durieux L, Lagabrielle E, Nelson A (2008) A method for monitoring building construction in urban sprawl areas using object-based analysis of Spot 5 images and existing GIS data. ISPRS J Photogramm Remote Sens 63(4):399-408. doi:10.1016/j.isprsjprs.2008.01.005

Dutta D, Serker N, Warnitchai P (2005) Use of VHR remote sensing imagery for urban building and infrastructure inventory database for disaster risk analysis. In: Proceedings of the Map India 2005 and Geomatics 2005, Delhi, India, 7-9 February 2005

Ehrlich D, Tenerelli P (2013) Optical satellite imagery for quantifying spatio-temporal dimension of physical exposure in disaster risk assessments. Nat Hazards 68(3):1271-1289

Ehrlich D, Gunter Z, Gallego J, Gerhardinger A, Caravaggi I, Pesaresi M (2010) Quantifying the building stock from optical high-resolution satellite imagery for assessing disaster risk. Geocarto Int 25(4):281-293

Ehrlich D, Kemper T, Blaes X, Soille P (2013) Extracting building stock information from optical satellite imagery for mapping earthquake exposure and its vulnerability. Nat Hazards 68(1):79-95. doi:10.1007/ s11069-012-0482-0

Elwood S (2008) Volunteered geographic information: future research direction motivated by critical, participatory, and feminist GIS. GeoJournal 72(3-4):173-183

FEMA (The Federal Emergency Management Agency) (1999) Earthquake loss estimation methodologyHAZUS 99. Washington, D.C. http://www.disastersrus.org/emtools/earthquakes/FEMA366.pdf. Accessed 15 Sept 2009

Fisher G, Amos C, Bookhagen B, Burbank D, Godard V (2012) Channel widths, landslides, faults, and beyond: the new world order of high-spatial resolution Google Earth imagery in the study of earth surface processes. Geol Soc Am Special Pap 492:1-22. doi:10.1130/2012.2492(01)

Foody G, See L, Fritz S, Van der Velde M, Perger C, Schill C, Boyd D (2013) Assessing the accuracy of volunteered geographic information arising from multiple contributors to an internet based collaborative project. Trans GIS 17(6):847-860. doi:10.1111/tgis.12033

Gao SL, Wu JL (2014) The application of the earthquake disaster display base on Google Earth. Seismol Geomagn Obs Res 35(1/2):268-275 (in Chinese with English abstract)

Gao H, Barbier G, Goolsby R (2011) Harnessing the crowdsourcing power of social media for disaster relief. IEEE Intell Syst 26(3):10-14. doi:10.1109/MIS.2011.52

Geiß C, Taubenböck H (2013) Remote sensing contributing to assess earthquake risk: from a literature review towards a roadmap. Nat Hazards 68(1):7-48

Geiß C, Taubenböck H, Tyagunov S, Tisch A, Post J, Lakes T (2014) Assessment of seismic building vulnerability from space. Earthquake Spectra 30(4):1553-1583. doi:10.1193/121812EQS350M

Geiß C, Aravena Pelizari P, Marconcini M, Sengara W, Edwards M, Lakes T, Taubenböck H (2015) Estimation of seismic buildings structural types using multi-sensor remote sensing and machine learning techniques. ISPRS J Photogramm Remote Sens 104:175-188. doi:10.1016/j.isprsjprs.2014.07. 016

Geiß C, Jilge M, Lakes T, Taubenböck H (2016) Estimation of seismic vulnerability levels of urban structures with multisensor remote sensing. IEEE J Sel Top Appl Earth Obs Remote Sens 9(5):1913-1936

Ghaffarian S, Ghaffarian S (2014) Automatic building detection based on supervised classification using high resolution Google Earth images. The international archives of the photogrammetry, remote sensing and spatial information sciences, Volume XL-3, ISPRS technical commission III symposium, 5-7 Sept 2014, Zurich, Switzerland

Gianinetto M (2008) Updating large scale topographic databases in Italian urban areas with submeter QuickBird images. Int J Navig Obs. doi:10.1155/2008/725429 
Gill A, Bunker D (2012) Crowd sourcing challenges assessment index for disaster management. In: AMCIS 2012 proceedings. Paper 21. http://aisel.aisnet.org/amcis2012/proceedings/EGovernment/21

Godeyes (2007) Google Earth GetScreen. http://www.godeyes.cn/html/2007/04/09/download_643.html. Accessed 10 Oct 2015 (in Chinese)

Goodchild M (2007) Citizens as sensors: the world of volunteered geography. GeoJournal 69:211-221

Goodchild M (2008) The use cases of digital earth. Int J Digit Earth 1:31-42

Goodchild M, Glennon J (2010) Crowdsourcing geographic information for disaster response: a research frontier. Int J Digit Earth 3(3):231-241. doi:10.1080/17538941003759255

Gordon M (2014) Remote-sensing study of some earthquakes of the Qing Dynasty. M. Earth Sci. Dissertation, Department of Earth Sciences, Oxford University

Grünthal G (1998) European macroseismic scale 1998. European Center of Geodynamics and Seismology. http://media.gfz-potsdam.de/gfz/sec26/resources/documents/PDF/EMS-98_OrigiOri_englisch.pdf. Accessed 15 Sept 2009

Haworth B, Bruce E (2015) A review of volunteered geographic information for disaster management. Geogr Compass 9(5):237-250. doi:10.1111/gec3.12213

Hebei Daily (2010) Zhang Yunchuan put forward the main aims of the policy of "Great Changes within three years". http://he.people.com.cn/GB/197089/201792/201803/12597330.html. Accessed 3 Oct 2015 (in Chinese)

Heipke C (2010) Crowdsourcing geospatial data. ISPRS J Photogramm Remote Sens 65(6):550-557. doi:10. 1016/j.isprsjprs.2010.06.005

Horita F, Degrossi L, Assis L, Zipf A, Albuquerque J (2013) The use of volunteered geographic information and crowdsourcing in disaster management: a systematic literature review. In: Proceedings of the nineteenth americas conference on information system, Chicago, Illinois, August 15-17, 2013, pp 1-10

Huang HM, Zhou HJ, Chen YY, Bian YJ (2011) Seismic event labeling in the Google Earth by interactive user interface operation and by program. In: Zeng DH (ed) Applied informatics and communication. Springer, Berlin, pp 280-286. doi:10.1007/978-3-642-23220-6_34

Hyvärinen O, Saltikoff E (2010) Social media as a source of meteorological observations. Mon Weather Rev 138(8):3175-3184. doi:10.1175/2010MWR3270.1

IFN (International Financial News) (2013) SOSO street view exclusive mark local focal points for disaster relief in Yuyao, China. http://paper.people.com.cn/gjjrb/html/2013-10/14/content_1309182.htm. Accessed 15 Dec 2014 (in Chinese)

Inel M, Senel S, Toprak S, Manav Y (2008) Seismic risk assessment of buildings in urban areas: a case study for Denizli, Turkey. Nat Hazards 46(3):265-285

Kayen R, Steele WC, Collins B, Walker K (2008) Google Earth mapping of damage from the Niigata-KenChuetsu M6.6 earthquake of 16 July 2007. In: Proceedings of 6th international conference on case histories in geotechnical engineering Arlington, VA, America, 11-16 August 2008

Lang DH, Vladimir G (2010) RISe: illustrating geo-referenced data of seismic risk and loss assessment studies using Google Earth. Earthquake Spectra . doi:10.1193/1.3283906

Li J (2009) Global strong earthquake loss estimating model based on GDP, population and site correction in Google Earth. Dissertation, University of Science and Technology of China (in Chinese with English abstract)

Li DP, Sun JG, Hu XF (2007) The application of Digital Earth in earthquake protection and disaster reduction: a case about Google Earth. Seismol Geomagn Obs Res 28(2):90-96 (in Chinese with English abstract)

Li WL, Huang RQ, Pei XJ, Zhang XC (2015) Historical co-seismic landslides inventory and analysis using Google Earth: a case study of 1920 M8.5 Haiyuan earthquake, China. In: Lollino G, Giordan D, Crosta G, Corominas J, Azzam R, Wasowski J, Sciarra N (eds) Engineering geology for society and territory, vol 2. Springer, New York, pp 709-719. doi:10.1007/978-3-319-09057-3_118

Madadi MR, Azamathulla HM, Yakhkeshi M (2015) Application of Google Earth to investigate the change of flood inundation area due to flood detection dam. Earth Sci Inf 8(3):627-638. doi:10.1007/s12145014-0197-8

Mark S, Schorlemmer D (2016) What makes people respond to "Did you feel it?". Seismol Res Lett 87(1):119-131. doi:10.1785/0220150056

McDougall K (2011) Using volunteered information to map the Queensland floods. In: Proceedings of the Surveying and Spatial Sciences Biennial Conference: Innovation in Action: Working Smarter (SSSC 2011), 21-25 Nov 2011, Wellington, New Zealand, pp 13-23

Miura H, Midorikawa S (2006) Updating GIS building inventory data using high-resolution satellite images for earthquake damage assessment: application to Metro Manila, Philippines. Earthquake Spectra 22(1):151-168 
Miura H, Midorikawa S, Fujimoto K (2004) Automated building detection from high-resolution satellite image for updating GIS building inventory data. In: Proceedings of the 13th World Conference on Earthquake Engineering, Vancouver, BC, Canada, 1-6 August 2004; Paper No. 678

Mück M, Taubenböck H, Post J, Wegscheider S, Strunz G, Sumaryono S, Ismail FA (2013) Assessing building vulnerability to earthquake and tsunami hazard using remotely sensed data. Nat Hazards 68:97-114. doi:10.1007/s11069-012-0481-1

Mueller M, Segl K, Heiden U, Kaufmann H (2006) Potential of high-resolution satellite data in the context of vulnerability of buildings. Nat Hazards 38(1):247-258

Nourbakhsh I, Sargent R, Wright A, Cramer K, McClendon B, Jones M (2006) Mapping disaster zones. Nature 439:787-788

Ouzounis G, Pesaresi M, Soille P (2012) Differential area profiles: decomposition properties and efficient computation. IEEE Trans Pattern Anal Mach Intell 34(8):1533-1548. doi:10.1109/TPAMI.2011.245

Panagiota M, Erwan P, Philippe G, Jocelyn C (2012a) Seismic vulnerability assessment using support vector machine classification for remote sensing and in situ data. http://www.iitk.ac.in/nicee/wcee/article/ WCEE2012_5147.pdf. Accessed 15 Nov 2013

Panagiota M, Jocelyn C, Erwan P, Philippe G (2012b) A support vector regression approach for building seismic vulnerability assessment and evaluation from remote sensing and in situ data. In: Proceedings of the 2012 IEEE international geoscience and remote sensing symposium (IGARSS), Munich, Germany, 22-27 July 2012, pp 7533-7536

Pittore M, Wieland M (2013) Toward a rapid probabilistic seismic vulnerability assessment using satellite and ground-based remote sensing. Nat Hazards 68(1):115-145. doi:10.1007/s11069-012-0475-z

Ploeger S, Atkinson G, Samson C (2010) Applying the HAZUS-MH software tool to assess seismic risk in downtown Ottawa, Canada. Nat Hazards 53(1):1-20

Polli D, Dell' Acqua F (2011) Fusion of optical and SAR data for seismic vulnerability mapping of buildings. In: Prasad S, Bruce L, Chanussot J (eds) Advances in signal processing and exploitation techniques. Springer, Berlin Heidelberg, pp 329-341. doi:10.1007/978-3-642-14212-3_15

Polli D, Dell'Acqua F, Gamba P (2010) Seismic vulnerability assessment in the framework of GEO: A case study on Messina, Italy. In: Proceedings of the Gi4DM 2010 conference, geomatics for crisis management, Torino, Italy, 2-4 February 2010

Poser K, Dransch D (2010) Volunteered geographic information for disaster management with application to rapid flood damage estimation. Geomatica 64(1):89-98

Ruan PP, Jia AC (2013) Research on application of Google Earth in urban flood damage analysis. J Water Resour Archit Eng 11(6):213-216 (in Chinese with English abstract)

SAC (Standadization Administration of China) (2014) Chinese Standard GB/T 19428-2014: Code for earthquake loss estimation and its information management system. Standards Press of China, Beijing (in Chinese)

SAC (Standardization Administration of China) (2011) Chinese Standard GB/T 18208.4-2011: Postearthquake field works-part 4: assessment of direct loss. Standards Press of China, Beijing (in Chinese)

Sarabandi P, Kiremidjian A (2007) Development of algorithms for building inventory compilation through remote sensing and statistical inferencing; Report No. 158; The John A. Blume Earthquake Engineering Center, Department of Civil and Environmental Engineering, Stanford University: Stanford, CA, USA

Sato H, Harp E (2009) Interpretation of earthquake-induced landslides triggered by the 12 May 2008, M7.9 Wenchuan earthquake in the Beichuan area, Sichuan Province, China using satellite imagery and Google Earth. Landslides 6:153-159. doi:10.1007/s10346-009-0147-6

Schelhorn S, Herfort B, Leiner R, Zipf A, Albuquerque J (2014) Identifying elements at risk from OpenStreetMap: the case of flooding. In: Proceedings of the 11th international ISCRAM conference, University of Park, Pennsylvania, USA, May 18-21, 2014

Schnebele E, Cervone G (2013) Improving remote sensing flood assessment using volunteered geographical data. Nat Hazards Earth Syst Sci 13(3):669-677. doi:10.5194/nhess-13-669-2013

Shorter N, Kasparis T (2009) Automatic vegetation identification and building detection from a single nadir aerial image. Remote Sens 1:731-757

Shuai F, Xiao GR, Jie ZQ (2011) Faculty of geomatics application of Google Earth in geoscience research. J East China Inst Technol 34(1):89-93 (in Chinese with English abstract)

Stensgaard A, Saarnak CFL, Utzinger J, Vounatsou P, Simoonga C, Mushinge G, Rahbek C, Mohlenberg F, Kristensen TK (2009) Virtual globes and geospatial health: the potential of new tools in the management and control of vector-borne disease. Geospatial Health 3:127-144 
Su GW, Zhu L, Ma ZJ, Wu Q (2007) A preliminary study on the changes of the regioal scale macrosopic vulnerability to earthquake disasters of Beijing, Tianjin, and Tangshan area: spatial changes. Seimol Geol 29(1):15-33 (in Chinese with English abstract)

Su GW, Qi WH, Zhang SL, Sim T, Liu XS, Sun R, Sun L, Jin YF (2015) An integrated method combining remote sensing data and local knowledge for the large-scale estimation of seismic loss risks to buildings in the context of rapid socioeconomic growth: a case study in Tangshan, China. Remote Sens 7:2543-2601. doi:10.3390/rs70302543

Taubenböck H, Roth A, Dech S, Mehl H, Münich J, Stempniewski L, Zschau J (2009) Assessing building vulnerability using synergistically remote sensing and civil engineering. In: Krek A, Rumor M, Zlatanova S, Fendel E (eds) Urban and regional data management. Taylor \& Francis Group, London, pp 287-300. ISBN 978-0-415-55642-2

USGS (U.S. Geological Survey) (2015) Google Earth/KML files. http://earthquake.usgs.gov/learn/kml.php. Accessed 10 Oct 2015

Wald D, Quitoriano V, Dengler L, Dewey J (1999) Utilization of the internet for rapid community intensity maps. Seismol Res Lett 70(6):680-697

Wang WP (2015) Shaanxi will make three dimensional digital map of the whole province. http://hsb.hsw.cn/ system/2015/1217/29006.shtml. Accessed 20 Dec 2015 (in Chinese)

Webley PW, Dean K, Bailey JE, Dehn J, Peterson R (2009) Automated forecasting of volcanic ash dispersion utilizing virtual globes. Nat Hazards 51:345-361

Wieland M, Pittore M, Parolai S, Zschau J (2012) Exposure estimation from multi-resolution optical satellite imagery for seismic risk assessment. ISPRS Int J Geo-Inf 1(1):69-88. doi:10.3390/ijgi1010069

Yang DQ, Zhang DQ, Frank K, Robertson P, Jennings E, Roddy M, Lichtenstern M (2014) Providing realtime assistance in disaster relief by leveraging crowdsourcing power. Pers Ubiquit Comput 18(8):2015-2034. doi:10.1007/s00779-014-0758-3

Yin ZQ (1991) A study for predicting earthquake disaster loss. Earthquake Eng Eng Vib 11(4):87-96 (in Chinese with English abstract)

Yin ZQ (1995) The prediction method of earthquake disasters and losses. Seismological Press, Beijing (in Chinese)

Yin ZT, Zheng WF, Yang CH, Li XL, Li HR (2009) Application of Google Earth in the decision making of earthquake disaster prevention and reduction. J Seismol Res 32(1):99-103 (in Chinese with English abstract)

Yu L, Gong P (2012) Google Earth as a virtual globe tool for earth science applications at the global scale: progress and perspectives. Int J Remote Sens 33(12):3966-3986. doi:10.1080/01431161.2011.636081

Yuan ZX, Wang LM (2004) Application of high-resolution satellite image for seismic risk assessment. In: Proceedings of the 13th world conference on earthquake engineering, Vancouver, BC, Canada, 1-6 August 2004. Paper No. 3454

Zhang GF, Shan XJ, Yin JY (2005) Application of high-resolution satellite remote sensing image in quick pre-estimate of seismic disaster. J Geodesy Geodyn 25(2):63-68 (in Chinese with English abstract)

Zhang GF, Shan XJ, Yin JY, Ma ZS, Zhao JJ (2007) The method to extract urban buildings' height and location from single high resolution aerial imagery. Seismol Geol 29(1):180-187 (in Chinese with English abstract)

Zhao Q, Zhai YM, Li TZ (2012) Study on application of high resolution remote sensing images in rapid prediction of earthquake disaster in urban area. J Catastrophol 27(2):72-76 (in Chinese with English abstract)

Zhou CH, Luo JC (2009) Geosciences computation method of high resolution satellite remote sensing image. Science Press, Beijing (in Chinese)

Zook M, Graham M, Shelton T, Gorman S (2010) Volunteered geographic information and crowdsourcing disaster relief: a case study of the Haitian Earthquake. World Med Health Policy 2(2):7-33 